\title{
DFT studies on one-electron oxidation and one-electron reduction for 2- and 4-aminopyridines
}

\author{
Ewa D. Raczyńska • Tomasz M. Stępniewski • \\ Katarzyna Kolczyńska
}

Received: 27 January 2012 / Accepted: 23 April 2012 / Published online: 15 May 2012

(C) The Author(s) 2012. This article is published with open access at Springerlink.com

\begin{abstract}
Quantum-chemical calculations \{DFT(B3LYP)/ $6-311+\mathrm{G}(\mathrm{d}, \mathrm{p})\}$ were performed for all possible tautomers (aromatic and nonaromatic) of neutral 2- and 4aminopyridines and their oxidized and reduced forms. One-electron oxidation has no important effect on the tautomeric preference for 2-aminopyridine. The amine tautomer is favored. However, oxidation increases the stability of the imine $\mathrm{NH}$ tautomer, and its contribution in the tautomeric mixture cannot be neglected. In the case of 4-aminopyridine, one-electron oxidation increases the stability of both the amine and imine NH tautomers. Consequently, they possess very close energies. As major tautomers, they dictate the composition of the tautomeric mixture. The $\mathrm{CH}$ tautomers may be considered as very rare forms for both neutral and oxidized aminopyridines. A reverse situation takes place for the reduced forms of aminopyridines. One-electron reduction favors the $\mathrm{C} 3$ atom for the labile proton for both aminopyridines. This may partially explain the origin of the $\mathrm{CH}$ tautomers for the anionic states of nucleobases containing the exo $\mathrm{NH}_{2}$ group.
\end{abstract}

E. D. Raczyńska $(\bowtie)$

Department of Chemistry,

Warsaw University of Life Sciences (SGGW),

ul. Nowoursynowska $159 \mathrm{c}$,

02-776 Warsaw, Poland

e-mail: ewa_raczynska@sggw.pl

T. M. Stępniewski $\cdot$ K. Kolczyńska

Interdisciplinary Department of Biotechnology,

Warsaw University of Life Sciences (SGGW),

ul. Nowoursynowska 166 ,

02-776 Warsaw, Poland
Keywords Aminopyridines $\cdot$ DFT $\cdot \mathrm{N}$-aza effects $\cdot \mathrm{NH}$ and $\mathrm{CH}$ tautomers · One-electron oxidation · One-electron reduction $\cdot \pi$-Electron delocalization

\section{Introduction}

Intramolecular proton transfer, called prototropic tautomerism or prototropy, is the simplest process that occurs for natural products (bioamines such as histamine, amino acids such as histidine and arginine, nucleobases such as cytosine, thymine, uracil, adenine, and guanine, porphyrins, etc.) [1-5]. This elementary conversion dictates their structure, acid-base properties, hydrogen bond formation, solvent interactions, and other physicochemical properties. It influences also the mechanism of many chemical reactions and biochemical transformations, including those involving specific interactions with proteins, enzymes, and receptors.

To understand prototropic tautomerism for nucleobases possessing the exo $\mathrm{NH}_{2}$ group (cytosine and adenine given in Fig. 1), it is very important to understand first the tautomeric conversions for their model compounds. For our investigations, we chose the neutral and unpaired ionic forms of convenient models - six membered rings with the exo $\mathrm{NH}_{2}$ group and the endo $\mathrm{N}$-aza atom(s). In our previous papers, we studied the enamine-imine conversions for the neutral and redox forms of aniline (AN) [6] and the amineimine and enamine-imine conversions for the neutral and redox forms of 4-aminopyrimidine (4APM) [7]. We found an interesting change of the tautomeric preference for the unpaired anions. To complete these studies for model aminoazines and to analyze effects of the $\mathrm{N}$-aza group(s), we chose 2- (2APY) and 4-aminopyridines (4APY). We 
<smiles>Nc1cc[nH]c(=O)n1</smiles>

Cytosine (C)<smiles>Nc1ccccn1</smiles>

2-Aminopyridine (2APY)<smiles>Nc1ncnc2[nH]cnc12</smiles>

Adenine (A)<smiles>Nc1ccncc1</smiles>

4-Aminopyridine (4APY)

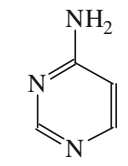

4-Aminopyrimidine (4APM)
Fig. 1 Nucleobases with the $\mathrm{NH}_{2}$ group and their convenient models

applied the same methods as previously described for $\mathbf{A N}$ and 4APM $[6,7]$.

In the literature, one can find numerous papers for neutral aminopyridines. For example, tautomeric equilibria for their methyl derivatives have been theoretically studied using the DFT, PCM and SCI-PCM methods [8]. The amine form strongly dominates in the gas phase as well as in solution. The fixed imine form $\{2(1 \mathrm{H})$-pyridinimine $\}$ has been investigated for its 1-methyl derivative [9-13]. Alkorta and Elguero analyzed the dimerization of $\mathbf{2 A P Y}$ by the hydrogen bond formation and studied the dimerization effect on tautomeric equilibria using $a b$ initio methods [14]. They also discussed the substituent effects on the tautomeric preferences. Interesting studies have been carried out by chemists from Japan and Taiwan. They studied the hydrogen bonding and the imine form formation for the 2APY/ acetic acid system in the ground and excited state using various spectroscopic and quantum-chemical methods [15-20]. Photoinduced reversible amine-imine tautomerism has also been detected for $\mathbf{2 A P Y}$ and for its derivatives by Ar-matrix-isolation infrared spectroscopy and DFT calculations [21-23]. To our knowledge, there is no report on prototropy for redox forms of $\mathbf{2 A P Y}$ and $\mathbf{4 A P Y}$, which may be formed in the presence of various oxidizing and reducing agents.

In this paper, we studied the consequences of oneelectron oxidation and one-electron reduction on tautomeric equilibria and on composition of the tautomeric mixture for 2- (2APY) and 4-aminopyridine (4APY). We considered various oxidation states of aminopyridines, neutral (2APY and $\mathbf{4 A P Y})$, oxidized $\left(\mathbf{2} \mathbf{A P Y} \mathbf{Y}^{+\bullet}\right.$ and $\mathbf{4} \mathbf{A P Y} \mathbf{Y}^{+\bullet}$ ), and reduced state $\left(\mathbf{2} \mathbf{A P Y} \mathbf{Y}^{-}\right.$and $\left.\mathbf{4} \mathbf{A P Y} \mathbf{Y}^{\mathbf{*}}\right)$. To investigate variations of $\pi$ electron delocalization for the ring and for the whole tautomeric system, we analyzed the geometrical parameters of all possible tautomers for the neutral and ionic forms of aminopyridines. We discussed also the spin populations for heavy atoms in the ionic forms. We estimated the tautomeric equilibrium constants and the oxidation and reduction energies.
Finally, we compared our results with those reported previously for aniline [6] and 4-aminopyrimidine [7], and we discussed effects of the $\mathrm{N}$-aza group(s).

\section{Computational details}

Geometries of all neutral and ionic tautomers of 2- and 4aminopyridines were fully optimized without symmetry constraints employing the DFT(B3LYP) method [24-26] and the $6-311+\mathrm{G}^{* *}$ basis set [27]. For all neutral, oxidized, and reduced isomers, the DFT minima were found with all real frequencies and thermodynamic parameters such as the energy $(E)$, enthalpy $(H)$, entropy $(S)$, and Gibbs energy ( $G$ for $T=298.15 \mathrm{~K}$ ) were calculated at the same level of theory. All calculations were performed using the Gaussian 03 program [28].

\section{Results and discussion}

\section{Choice of methods}

For our investigations on prototropy for the neutral and redox forms of aminopyridines, we chose quantumchemical methods because experimental techniques are incapable of detecting less than $0.1 \%$ of minor tautomer(s) [15-23]. Tautomeric conversions are very fast and reversible processes, and thus it is difficult to separate and to study individual tautomers. Applying spectroscopic techniques such as ultraviolet (UV), infrared (IR), Raman, nuclear magnetic resonance (NMR), microwave (MW), mass spectrometry (MS), etc. to tautomeric mixtures one may identify signals of significant intensities solely for major tautomers ( $\mathrm{NH}$ forms). Minor tautomers ( $\mathrm{CH}$ forms) cannot be detected, because their amounts are too small $(<0.1 \%)$ and their signals are in the background.

We applied the DFT method [24] with the B3LYP functional $[25,26]$ and the $6-311+\mathrm{G}(\mathrm{d}, \mathrm{p})$ basis set with the diffuse and polarization functions [27]. The DFT method has been applied for proton transfer reactions, including the tautomeric conversions in the gas phase that models a polar environment [29-37]. However, it should be mentioned here that the B3LYP method should be very carefully used for tautomeric systems. In some cases, e.g., for amide-iminol equilibrium in 2-hydroxypyridine/2-pyridone, where the relative energies for the major tautomers are close to zero, the B3LYP predictions overestimate the experimental data [38]. Errors are slightly larger than $1 \mathrm{kcal} \mathrm{mol}^{-1}$. For this reason, we tested various levels of theory for aniline [6] - the parent system of azaanilines: B3LYP/6-311+G(d,p), B3LYP/6-311++G(3df,3pd), B3LYP/aug-cc-pVDZ, and G2, and we found that (i) the $\mathrm{B} 3 \mathrm{LYP} / 6-311+\mathrm{G}(\mathrm{d}, \mathrm{p})$ level is sufficient for the tautomeric 
systems of amino aromatics, (ii) the use of different basis set for DFT calculations has no important effect on the values of geometric and energetic parameters, and (iii) the DFT relative Gibbs energies are close to those at the G2 level, recommended for the proton-transfer reactions in the gas phase [39, 40].

Using the quantum-chemical methods, we can study all possible prototropic tautomers and all possible tautomeric conversions for various oxidation states of 2- and 4aminopyridines: the neutral state (APY), the unpaired cation $\left(\mathbf{A P Y}-\mathrm{e} \rightarrow \mathbf{A P Y}^{+\boldsymbol{*}}\right)$, and the unpaired anion (APY $+\mathrm{e} \rightarrow$ $\mathbf{A P Y}^{-}$). Transferring an electron from or to the tautomeric molecule may change the stabilities of individual tautomers, and consequently, the composition of the tautomeric mixture.

\section{Possible tautomeric equilibria}

Aminopyridines 2APY and 4APY contain two functional groups, the exo $\mathrm{NH}_{2}$ group and the endo $\mathrm{N}$-aza group which are $n-\pi$ and $\pi-\pi$ conjugated with the endo $>C=C<$ groups. They exhibit prototropic tautomerism. One labile proton can move from the exo $\mathrm{NH}_{2}$ group to the endo $\mathrm{N}$ or $\mathrm{C}$ atom. Combination of two types of conversions: amineimine $\{-\mathrm{NH}-\mathrm{C}(\mathrm{R})=\mathrm{N}-\rightarrow-\mathrm{N}=\mathrm{C}(\mathrm{R})-\mathrm{NH}-\}$ and enamineimine $\{>\mathrm{C}=\mathrm{C}(\mathrm{R})-\mathrm{NH}-\rightarrow>\mathrm{CH}-\mathrm{C}(\mathrm{R})=\mathrm{N}-\}$ tautomerism leads to six tautomeric equilibria for four tautomers (Scheme 1 and 2), one amine form with the labile proton at the exo $\mathrm{N}$ atom, and three imine form with the labile proton at the endo $\mathrm{N}$ and $\mathrm{C}$ atoms for the $\mathrm{NH}$ and $\mathrm{CH}$ tautomers, respectively. For all tautomers, the intramolecular proton-transfer is accompanied by migration of $\pi$ electrons.

Due to geometric isomerism of the exo = NH group in 2aminopyridine (Scheme 1), two isomers are possible for 2APY2-2APY4, one (a) with the imine $\mathrm{H}$ atom synperiplanar

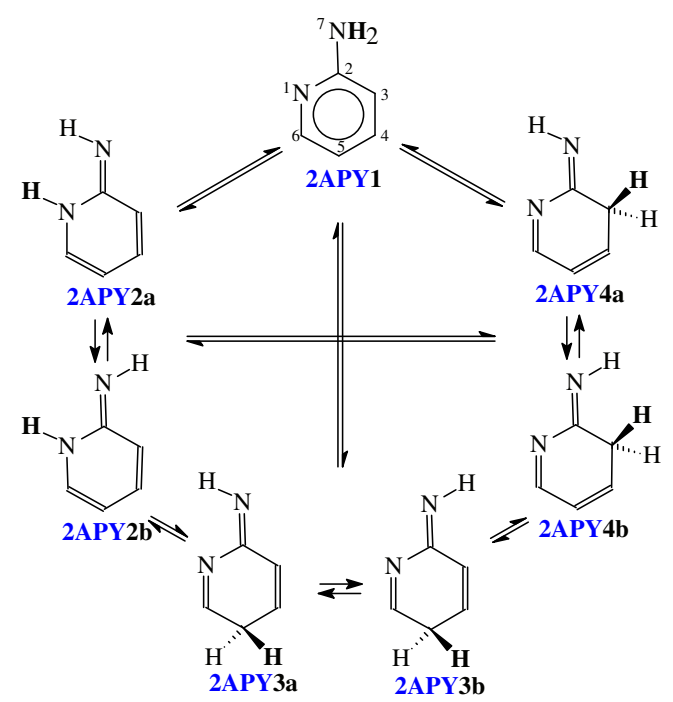

Scheme 1 Tautomeric equilibria for 2APY (labile proton marked in bold)

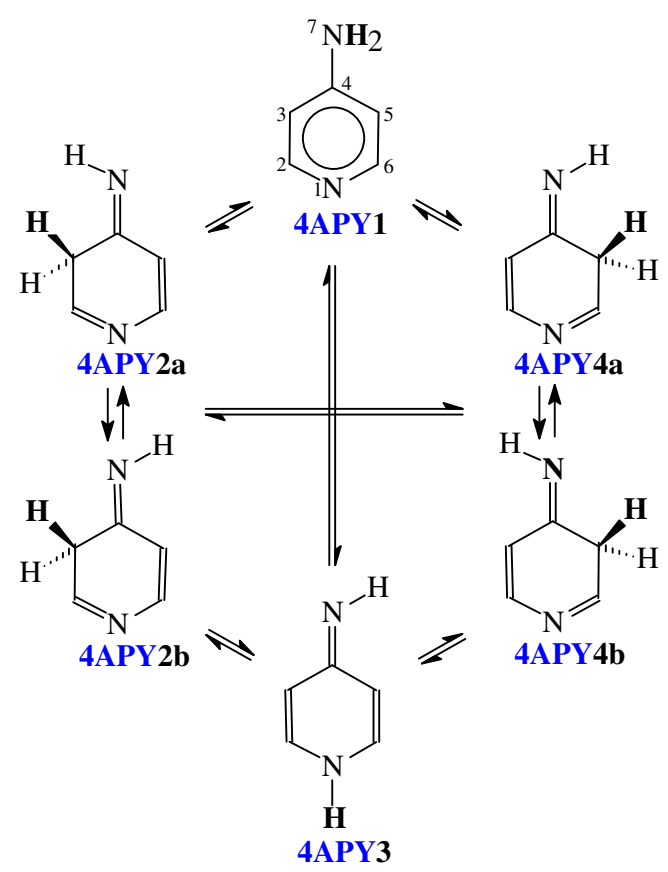

Scheme 2 Tautomeric equilibria for 4APY (labile proton marked in bold)

to the ring $\mathrm{N} 1$ atom and the other one (b) with the imine $\mathrm{H}$ atom antiperiplanar to the ring N1 atom. Similarly, two isomers are possible for the imine forms 4APY2 and 4APY4 of 4-aminopyridine (Scheme 2), one (a) with the imine $\mathrm{H}$ atom synperiplanar to the ring $\mathrm{C} 3$ (for 4APY2) and C5 (for 4APY4) atom, and the other one (b) with the imine $\mathrm{H}$ atom antiperiplanar. The structures 4APY2a and 4APY4a, and also 4APY2b and 4APY4b are identical for 4-aminopyridine, and thus the tautomeric equilibrium constants $K_{\mathrm{T}}$ for the conversions 4APY2a $\rightarrow$ 4APY4a and 4APY2b $\rightarrow$ 4APY4b are equal to unity. However, to estimate well the composition of the tautomeric mixture, all isomers (4APY1-4APY4) should be considered for 4-aminopyridine. In the literature, four tautomers have been solely considered for the neutral forms of methyl derivatives of aminopyridines [8].

\section{DFT structures}

For all isomers of neutral and ionic 2APY and 4APY (Scheme 1 and 2), the minima with all real frequencies were found at the B3LYP/6-311+G** level. As expected [6, 7], the exo $\mathrm{NH}_{2}$ group is planar solely for the unpaired cations $\mathbf{2 A P Y}^{+\bullet}$ and $4 \mathrm{APY} 1^{+\bullet}$. For neutral 2APY1 and 4APY1, and for unpaired anions $\mathbf{2} \mathbf{A P Y} \mathbf{1}^{-\boldsymbol{*}}$ and $\mathbf{4 A P Y} \mathbf{1}^{-\bullet}$, this group takes the pyramidal conformation similar to that for the neutral and anionic forms of aniline and 4-aminopyrimidine $[6,7,41$, 42]. Our results confirm the nonplanarity of the exo $\mathrm{NH}_{2}$ group for neutral aminopyridines discussed earlier in the literature $[43,44]$. Transfer of the proton to the endo $\mathrm{N}$ atom 
does not destroy the planarity of the ring for the neutral $\mathrm{NH}$ tautomers (2APY2a, 2APY2b, and 4APY3) and for their

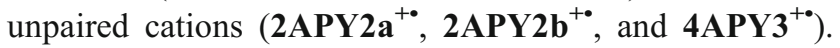
Some exceptions are the unpaired anions (2APY2 $\mathbf{a}^{-\mathbf{0}}$, $\mathbf{2 A P Y} \mathbf{2} \mathbf{b}^{-\boldsymbol{*}}$, and $\mathbf{4} \mathbf{A P Y} \mathbf{3}^{-\boldsymbol{}}$ ) for which the endo $\mathrm{N}$ atom takes the pyramidal conformation. Due to presence of the $\mathrm{C}-\mathrm{sp}^{3}$ atom (C3 and $\mathrm{C} 5$ ), all neutral $\mathrm{CH}$ isomers (2APY3a, 2APY3b, 2APY4a, 2APY4b, 4APY2a/4a, and 4APY2b/ 4b), their unpaired cationic (2APY3a ${ }^{+\bullet}, \mathbf{2 A P Y} 3 \mathbf{b}^{+\bullet}$, $2 \mathrm{APY}_{4} \mathrm{a}^{+\bullet}, 2 \mathrm{APY} 4 \mathrm{~b}^{+\bullet}, 4 \mathrm{APY} 2 \mathrm{a} / \mathbf{4 a}^{+\bullet}$, and $4 \mathrm{APY} 2 \mathrm{~b} / 4 \mathrm{~b}^{+{ }^{+}}$)

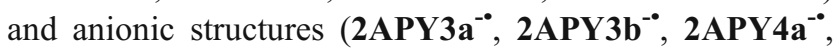
2APY 4 $b^{-*}, 4 A P Y 2 a / 4 a^{-*}$, and $\left.4 A P Y 2 b / 4 b^{-\bullet}\right)$ lose their planarity.

The DFT-calculated CC and $\mathrm{CN}$ bond lengths for the neutral and redox isomers of 2- and 4-aminopyridines are given in Figs. 2 and 3, respectively. For neutral 2APY1, 2APY2a, and 2APY2b, they are close to those calculated by Akai et al. [21] at the B3LYP/6-31++G(d,p) level. Differences in bond lengths are not larger than $0.01 \AA$. Variations of the $\mathrm{CC}$ and $\mathrm{CN}$ bond lengths for the neutral and charged isomers of aminopyridines are also similar to those previously observed for aniline [6] and 4-aminopyrimidine [7]. Generally, the CC bond lengths for 2APY and 4APY vary from 1.34 to $1.52 \AA$ for the neutral isomers, from 1.35 to $1.58 \AA$ for the unpaired cations, and from 1.35 to $1.55 \AA$ for the unpaired anions. Variations of the $\mathrm{CN}$ bond lengths are as follows: 1.27-1.43, 1.24-1.41, 1.30$1.43 \AA$ A, respectively.

When proceeding from the neutral isomers to their charged ions, the $\mathrm{CC}$ and $\mathrm{CN}$ bond lengths vary by 0.0 $0.9 \AA$ for the radical cations and by $0.0-0.7 \AA$ for the radical anions. These variations influence $\pi$-electron delocalization in the ring (six atoms) and also in the whole tautomeric system (seven atoms including the exo $\mathrm{N}$ atom). In this paper, we quantitatively measured the changes of $\pi$ electron delocalization by means of the geometry based harmonic oscillator model of electron delocalization (HOMED) index [6, 7, 35, 45-48] which describes well any type of conjugation $(\pi-\pi, n-\pi$, and $\sigma-\pi)$ possible in heteroatomic systems. This index was applied here to the DFT-calculated bond lengths.

\section{HOMED indices}

The HOMED procedure has been described in detail in ref [46] and applied to various cyclic and acyclic $\pi$-electron systems containing heteroatoms $[6,7,35,45-48]$. The HOMED index is based on the original harmonic oscillator model of aromaticity (HOMA) index [49, 50]. The HOMA index reformulated in 1993 [51] seems to be inappropriate for $\pi$-electron delocalized systems containing heteroatoms. The main reason is a use of different measures of $\pi$-electron delocalization for the reference $\mathrm{CC}$ and $\mathrm{CX}$ bonds $[6,7,35$, 45-48]. The reformulated HOMA index can be solely applied for homoaromatics. Its application to heteroaromatics leads to artificial positive or negative values for well delocalized $\pi$-electron systems [46].

The HOMED index can be estimated on the basis of the theoretically derived bond lengths using the following equation: HOMED $=1-\left[\alpha \cdot \Sigma\left(R_{\mathrm{o}}-R_{\mathrm{i}}\right)^{2}\right]: n \quad[45,46]$. This equation is similar to that for the reformulated HOMA index [51], but the values of its parameters ( $\alpha$ and $R_{\mathrm{o}}$ ) are different. In this equation, $\alpha$ is a normalization constant, $R_{\mathrm{O}}$ is the optimum bond length (assumed to be realized for fully delocalized system), $R_{\mathrm{i}}$ are the running bond lengths in the system, and $n$ is the number of bonds taken into account. The following $R_{\mathrm{o}}$ values (in $\AA$ ), calculated at the B3LYP/6-311+G(d,p) level [46], were taken here: 1.394 (benzene) and 1.334 (1,3,5triazine) for the $\mathrm{CC}$ and $\mathrm{CN}$ bonds, respectively. Similarly as in the case of aniline [6], 4-aminopyrimidine [7], and other heteroaromatic molecules [46], the normalization $\alpha$ constants equal to 88.09 (CC) and $91.60(\mathrm{CN})$ were used for the ring (six bonds), and 80.90 (CC) and $84.52(\mathrm{CN})$ for the whole tautomeric system (seven bonds including the exo $\mathrm{N}$ atom). The $\alpha$ constants differ from those employed for the reformulated HOMA index, because of use of simple only slightly delocalized reference CC (ethane and ethene [46] instead of 1,3butadiene [51]) and $\mathrm{CN}$ bonds (methylamine and methylimine $[46,51])$, and different procedures for the even and odd number of bonds in the system [6, 7, 45, 46]. For estimation of the $\alpha$ constants, the reference $\mathrm{CC}$ and $\mathrm{CN}$ bond lengths were calculated at the B3LYP/6-311+G(d,p) level.

Similarly as for aniline [6] and 4-aminopyrimidine [7], the HOMED indices, estimated for the neutral isomers, are close to unity for the amine tautomers 2APY1 (Fig. 4) and 4APY1 (Fig. 5). Due to cross $\pi-\pi$ and $n-\pi$ conjugations possible in the whole tautomeric system, i.e., conjugation of n-electrons of the exo $\mathrm{NH}_{2}$ group with $\pi$-electrons of the ring, the HOMED indices decrease when going from the ring (six bonds) to the whole tautomeric system (seven bonds). Transfer of the proton to the endo $\mathrm{N}$ and $\mathrm{C}$ atom decreases the HOMED indices by 0.2-0.3 and 0.6-0.7 units, respectively. The imine NH isomers (2APY2a, 2APY2b, and 4APY3) are less delocalized than the amine tautomers (2APY1 and 4APY1), but more delocalized than the imine CH isomers (2APY3a, 2APY3b, 2APY4a, 2APY4b, 4APY2a/4a, and 4APY2b/4b). The N1 atom taking the labile proton retains its planarity in the neutral form due to $\mathrm{n}-\pi$ conjugation similar to that for the $\mathrm{N} 1$ atom in the five membered ring of pyrrole, pyrazole, imidazole, etc., whereas the $\mathrm{C} 3$ and $\mathrm{C} 5$ atoms $\left(\mathrm{C}-\mathrm{sp}^{3}\right)$, taking the labile proton, lose their planarity. For the imine $\mathrm{CH}$ isomers, $\pi$-electrons of the $\pi-\pi$ conjugated $-\mathrm{C}=\mathrm{N}-\mathrm{C}=\mathrm{N}-\mathrm{C}=\mathrm{NH}$ fragment are 


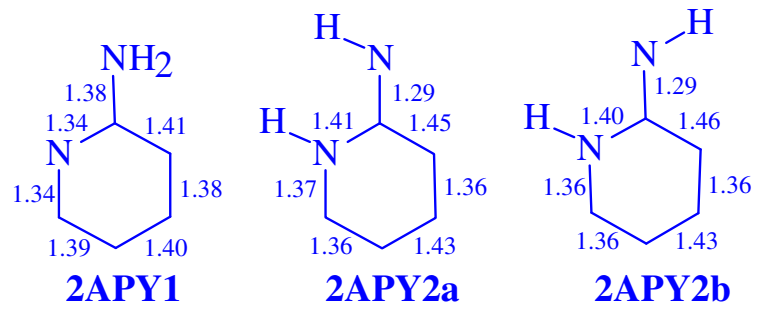

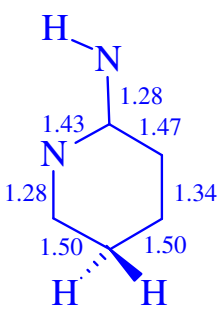

2APY3a

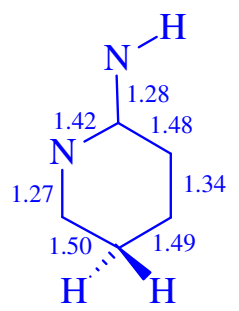

2APY3b<smiles>N=C1[CH]CCCN1</smiles>

2APY4a<smiles>N=C1CCCCN1</smiles>

2APY4b<smiles>NC1CCCCN1</smiles><smiles>NC1CCCCC1N</smiles><smiles>NC1CCCCN1</smiles><smiles>N=C1CCCCCN1</smiles><smiles>NC1CC[C@H]2CNC1C2</smiles>

2APY3a+

$2 A P Y 3 b^{+}$<smiles>N=C1[CH]CCCN1</smiles>

2APY $4 a^{+}$•<smiles>N=C1[CH]CCCN1</smiles>

2APY 4b ${ }^{+}$•<smiles>NC1=NCCCC1</smiles>

2APY1 ${ }^{-}$<smiles>N=C1CCCCN1</smiles>

2APY2a ${ }^{-}$<smiles>N=C1CCCCN1</smiles>

2APY $2 b^{-}$.<smiles>N=C1CC[CH]CN1</smiles>

2APY3a ${ }^{-\bullet}$<smiles>NC1CCCCNC1</smiles>

2APY3b ${ }^{-}$.<smiles>N=C1[CH]CCCN1</smiles>

2APY4a ${ }^{-}$.<smiles>N=C1CCCCN1</smiles>

2APY4b ${ }^{-\bullet}$

Fig. 2 The DFT-calculated CC and CN bond lengths (in $\AA$ ) for isomers of neutral $\mathbf{2 A P Y}$ and its unpaired ions $\mathbf{2} \mathbf{A P Y}^{+\bullet}$ and $\mathbf{2} \mathbf{A P Y}^{\bullet}$ 


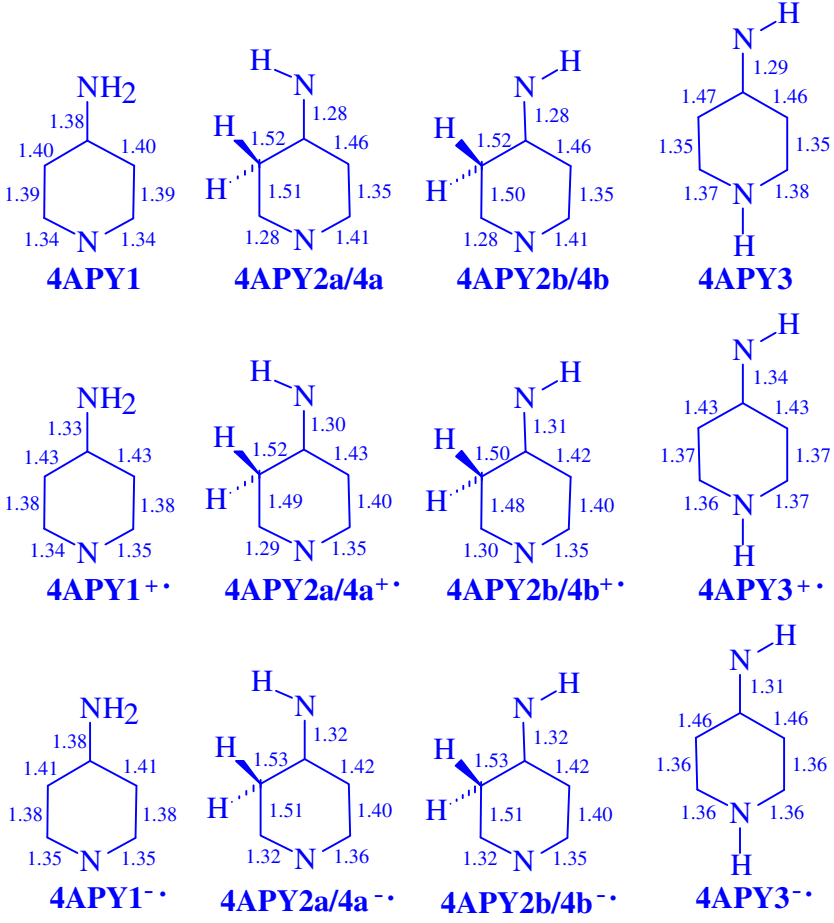

Fig. 3 The DFT-calculated $\mathrm{CC}$ and $\mathrm{CN}$ bond lengths (in $\AA$ ) for isomers of neutral $\mathbf{4 A P Y}$ and its unpaired ions $\mathbf{4} \mathbf{A P Y}^{+\bullet}$ and $\mathbf{4} \mathbf{A P Y}^{\cdot}$

cross hyperconjugated with $\sigma$-electrons of the $\mathrm{CH}_{2}$ group. Usually, $\sigma-\pi$ hyperconjugation leads to smaller electron delocalization than $\pi-\pi$ and $n-\pi$ conjugations [46]. Thus, the imine $\mathrm{NH}$ tautomers are still aromatic but the imine $\mathrm{CH}$ tautomers already have nonaromatic character.

One-electron oxidation and also one-electron reduction decrease aromaticity of the amine tautomers (2APY1 and 4APY1). The HOMED indices are reduced by less than 0.1

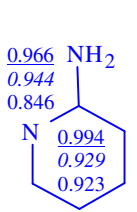

2APY1

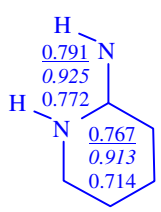

2APY2a

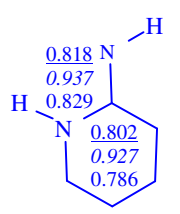

2APY2b

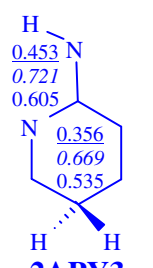

2APY3a

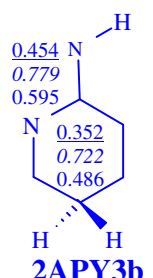

2APY3b

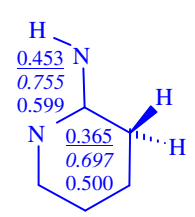

2APY4a

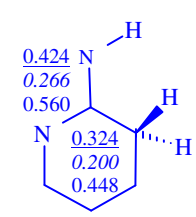

2APY4b
Fig. 4 The HOMED indices estimated for the DFT-structures of neutral (underlined values), oxidized (values in italic style), and reduced forms (values in normal style) of 2APY for the ring (six bonds, values included in the ring) and for the whole tautomeric system (seven bonds, values placed near the formula)
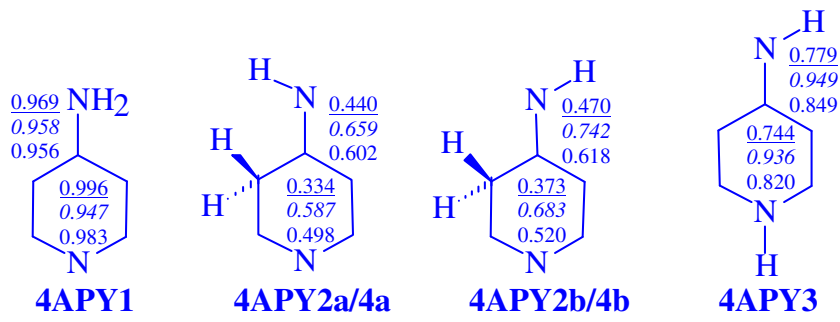

Fig. 5 The HOMED indices estimated for the DFT-structures of neutral (underlined values), oxidized (values in italic style), and reduced forms (values in normal style) of 4APY for the ring (six bonds, values included in the ring) and for the whole tautomeric system (seven bonds, values placed near the formula)

units. On the other hand, one-electron oxidation increases the HOMED indices for the imine $\mathrm{NH}$ tautomers (2APY2a, 2APY2b, and 4APY3) by 0.1-0.2 units increasing also their aromatic character. One-electron reduction has a slight effect. It changes the HOMED indices for the $\mathrm{NH}$ tautomers by less than \pm 0.1 units. Interestingly, for the imine $\mathrm{CH}$ tautomers (2APY3a, 2APY3b, 2APY4a, 2APY4b, 4APY2a/4a, and 4APY $2 b / 4 b$ ), both one-electron oxidation and oneelectron reduction increase the HOMED indices, but by different degree (by 0.2-0.4 and 0.1-0.2 units, respectively). For some cationic $\mathrm{CH}$ isomers (e.g., 2APY3a ${ }^{+\bullet}$, $2 \mathrm{APY} \mathrm{b}^{+\bullet}, \mathbf{2 A P Y} 4 \mathrm{a}^{+\bullet}$, and $\left.4 \mathrm{APY} 2 \mathrm{~b} / \mathbf{4 b}^{+\bullet}\right)$, the HOMED indices for the whole tautomeric system (seven bonds) are even close to 0.8 , indicating exceptional $\pi$-electron delocalization.

Spin densities

Some additional information on delocalization of one unpaired electron may be derived on the basis of the distribution of the unpaired spin density calculated for the charged radicals of aminopyridines. The total atomic spin densities calculated at the DFT/B3LYP/6-311+G(d,p) level for seven heavy atoms in $\mathbf{2} \mathbf{A P Y}^{+\boldsymbol{\bullet}}$ and $\mathbf{2} \mathbf{A P Y} \mathbf{P Y}^{\boldsymbol{*}}$, also in $\mathbf{4} \mathbf{A P Y} \mathbf{P}^{+\boldsymbol{\bullet}}$ and 4APY $^{*}$ are given in Figs. 6 and 7, respectively. Unfortunately, there is no experimental data for the aminopyridine charged radicals and no comparison can be made. Our DFT calculations indicate that the spin density exists on all atoms of the charged radicals. In the case of the amine radical cations $\mathbf{2} \mathbf{A P Y}^{+\bullet}$ and $\mathbf{4} \mathbf{A P Y} 1^{+\bullet}$, most of the density is carried by the $\mathrm{N} 1$ and $\mathrm{N} 7$ atoms, and also by the $\mathrm{C} 3$ and $\mathrm{C} 5$ atoms. On the $\mathrm{C} 2, \mathrm{C} 4$, and $\mathrm{C} 6$ atoms, a spin population is also present, but it is negative or close to zero. For the amine radical anions $\mathbf{2} \mathbf{A P Y} \mathbf{1}^{-\boldsymbol{*}}$ and $\mathbf{4} \mathbf{A P Y} \mathbf{1}^{-\boldsymbol{*}}$, most of the density is localized on the $\mathrm{C} 2, \mathrm{C} 4$, and $\mathrm{C} 6$ atoms. On the other atoms, a spin population also exists, but it is considerably lower or negative.

For the imine tautomers, the distribution of the spin density depends on the position of the labile proton and 
Fig. 6 The DFT atomic spin populations for seven heavy atoms present in the ionic forms of $2 \mathrm{APY}$, the radical cations $\left(\mathbf{2} \mathbf{A P Y}^{+\bullet}\right)$ and the radical anions $\left(2 \mathrm{APY}^{-*}\right)$

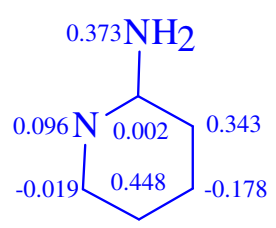

2APY1+.

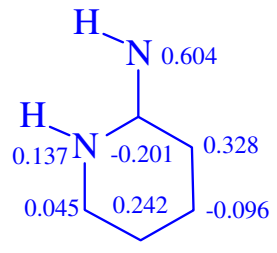

2APY2a +•

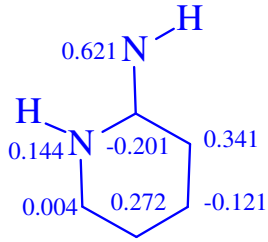

2APY $2 b^{+}$•<smiles>NC1CCCCN1</smiles>

2APY3a+

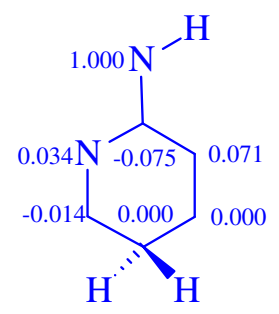

2APY3b + •

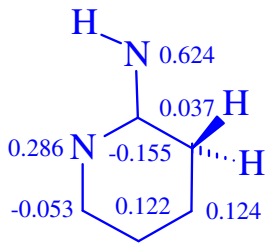

2APY4a ${ }^{+} \cdot$

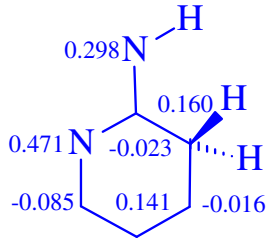

$2 \mathrm{APY} 4 \mathrm{~b}^{+}{ }^{+}$

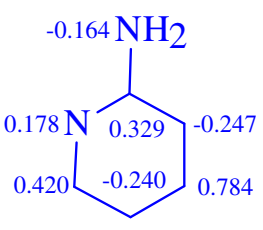

2APY1 ${ }^{-}$.

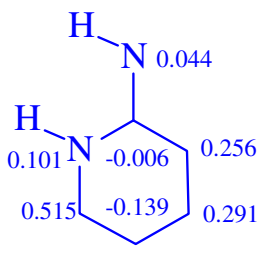

2APY2a ${ }^{-}$.

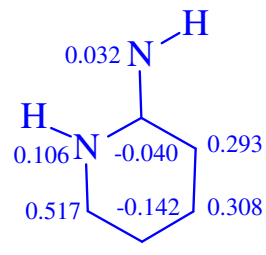

2APY2b ${ }^{-}$.

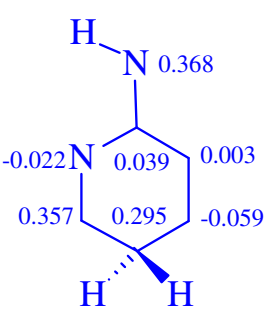

2APY3a ${ }^{-}$.

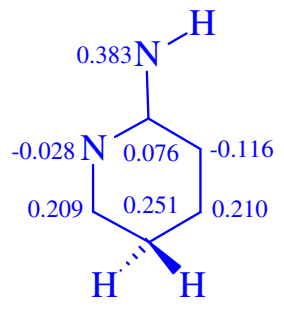

2APY3b ${ }^{-}$.

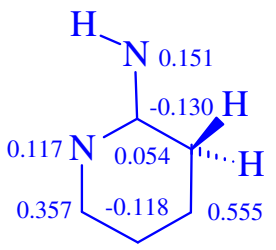

2APY4a-

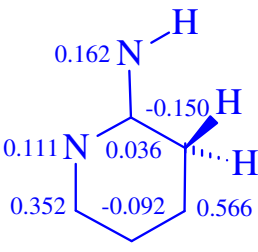

2APY4b ${ }^{-}$. charge. In the case of the imine $\mathrm{NH}$ radical cations $\mathbf{2} \mathbf{A P Y 2}^{+{ }^{+}}$ and $\mathbf{A A P Y}^{+\boldsymbol{\bullet}}$, most of the spin density is carried by the N7, $\mathrm{N} 1, \mathrm{C} 3$, and $\mathrm{C} 5$ atoms. For the other $\mathrm{C}$ atoms the spin density values are negative or close to zero. For the imine $\mathrm{NH}$ radical anions, the $\mathrm{C} 6, \mathrm{C} 4$, and $\mathrm{C} 3$ atoms take most of the spin density in $\mathbf{2} \mathbf{A P Y} \mathbf{2}^{-\mathbf{*}}$, and the $\mathrm{C} 3$, $\mathrm{C} 5$, and $\mathrm{C} 4$ atoms in $\mathbf{4} \mathbf{A P Y} 3^{-*}$. A spin population also

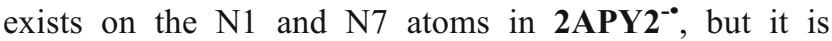
considerably lower. On the other atoms, the spin density values are negative. For the imine $\mathrm{CH}$ radical cations, most of the spin density is located on the $\mathrm{N} 7$ atom in $\mathbf{2 A P Y 3}^{+\boldsymbol{\bullet}}$, on the N7, N1, C3, or C5 atom in $\mathbf{2} \mathbf{A P Y}^{+{ }^{+}}$, and on the N7, N1, C5, and C2 atom in $\mathbf{4 A P Y 2} \mathbf{2}^{+\bullet}$. For the imine $\mathrm{CH}$ radical anions, most of the spin density is taken by the $\mathrm{N} 7, \mathrm{C} 5$, and $\mathrm{C} 6$ atoms in $\mathbf{2} \mathbf{A P Y}^{-}{ }^{-}$, by the $\mathrm{C} 4, \mathrm{C} 6, \mathrm{~N} 7$, and $\mathrm{N} 1$ atoms in $\mathbf{2 A P Y} \mathbf{4}^{-\mathbf{*}}$, and by the $\mathrm{C} 2$, $\mathrm{C} 5, \mathrm{C} 6$, and $\mathrm{N} 7$ atoms in $\mathbf{4 A P Y} \mathbf{2}^{-\bullet}$. For the other atoms, the spin density values are negative or close to zero.
Tautomeric preferences

As expected [6-8, 14-23], the amine tautomers 2APY1 and 4APY1 with the labile proton at the exo $\mathrm{N}$ atom has the lowest energy for neutral aminopyridines. Similar to aniline [6] and 4-aminopyrimidine [7], aromaticity of the six membered ring seems to be one of the most important factors that dictates the high stability of the neutral amine tautomers and their tautomeric preference $(100 \%)$ in the tautomeric mixture. Tables 1 and 2 summarize the relative thermodynamic parameters \{estimated at the B3LYP/6-311+G(d,p) level\} such as the relative energies $\left(\Delta E_{\mathrm{T}}\right)$, the relative enthalpies $\left(\Delta H_{\mathrm{T}}\right)$, the relative entropy terms $\left(T \Delta S_{\mathrm{T}}\right)$, the relative Gibbs energies $\left(\Delta G_{\mathrm{T}}\right)$, the tautomeric equilibrium constants (as $\left.\mathrm{p} K_{\mathrm{T}}=\Delta G_{\mathrm{T}} / 2.303 \mathrm{R} T\right)$, and the percentage contents $\left(x=K_{\mathrm{T}} /\right.$ $\left.\left(1+K_{\mathrm{T}}\right)\right\}$ of all individual neutral and ionic tautomers of 2and 4-aminopyridines, respectively. The $\Delta G$ values include changes in the electronic energy, in the zero-point energy 
Fig. 7 The DFT atomic spin populations for seven heavy atoms present in the ionic forms of $4 \mathrm{APY}$, the radical cations $\left(\mathbf{4} \mathbf{A P Y}^{+\bullet}\right)$ and the radical anions $\left(4 \mathrm{APY}^{\circ}\right)$
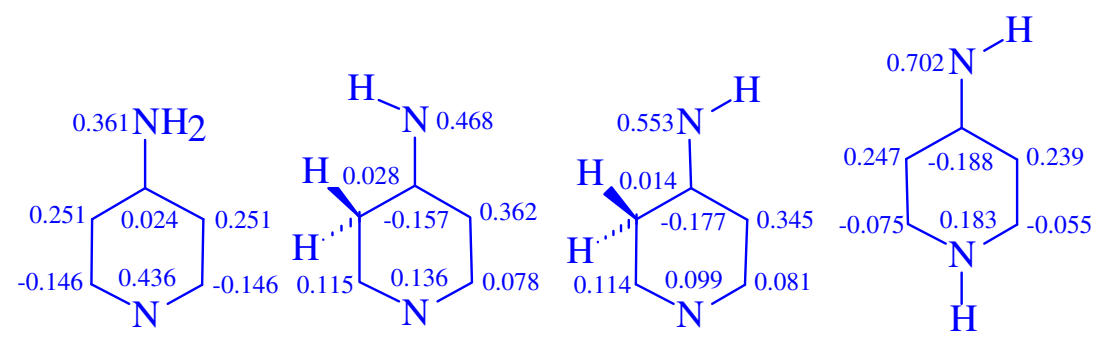

4APY1 ${ }^{+} \cdot$
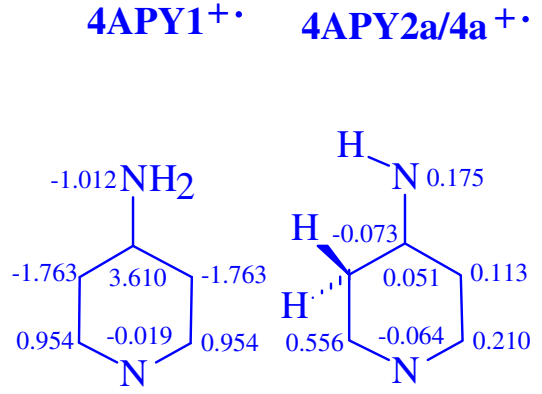

4APY1 ${ }^{-\bullet}$

4APY2a/4a ${ }^{-\cdot}$
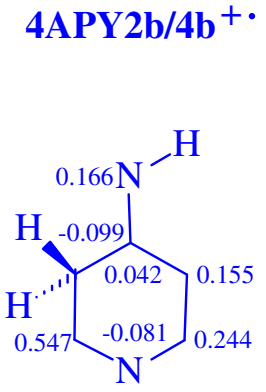

4APY2b/4b ${ }^{-\bullet}$
4APY3 $^{+\cdot}$

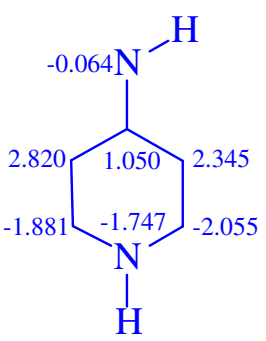

4APY3-•
(ZPE), and in the thermal corrections to the energy and entropy (vibrational, rotational, and translational).

The neutral imine NH tautomers 2APY2 and 4APY3 possessing the labile proton at the endo $\mathrm{N}$ atom have larger energies than 2APY1 and 4APY1 by 14-17 $\mathrm{kcal} \mathrm{mol}^{-1}$ at the B3LYP/6-311+G(d,p) level. Energetically favorable and energetically unfavorable interactions possible for the structures $\mathbf{a}$ and $\mathbf{b}$ of the 2APY2 tautomer differentiate their energies by only $3 \mathrm{kcal} \mathrm{mol}^{-1}$. Slightly larger energy differences (4-5 $\mathrm{kcal} \mathrm{mol}^{-1}$ ) occur for the structures $\mathbf{a}$ and $\mathbf{b}$ of the imine CH tautomers 2APY3 and 2APY4. In the case of the imine $\mathrm{CH}$ tautomers 4APY2/4, this energy difference is not larger than $1 \mathrm{kcal} \mathrm{mol}^{-1}$. However, transfer of the labile proton to the endo $\mathrm{C}$ atom exceptionally decreases the stability of both isomers (a and b) of 2APY3, 2APY4, and 4APY2/4. Their energies are larger than that of 2APY1 and 4APY1 by 29-35 $\mathrm{kcal} \mathrm{mol}^{-1}$. The contributions of all imine $\mathrm{NH}$ and $\mathbf{C H}$ isomers in the tautomeric mixture of $\mathbf{2 A P Y}$ and 4APY are very low $\left(<1 \cdot 10^{-8} \%\right)$.

According to the DFT results, one-electron oxidation has no important effect on the tautomeric preference in the gas phase for 2-aminopyridine (Table 1). The amine tautomer 2APY $\mathbf{1}^{+\bullet}$ has the lowest energy. However, oxidation changes the relative energies for the imine tautomers, and consequently, it changes also the composition of the tautomeric mixture. For the imine $\mathrm{NH}$ tautomer, the relative

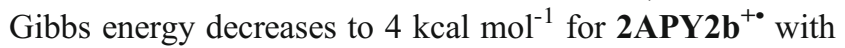
energetically favorable configurations and to $8 \mathrm{kcal} \mathrm{mol}^{-1}$ for $\mathbf{2 A P Y} \mathbf{2 a}^{+}{ }^{+}$with energetically unfavorable configurations. The reduction of the relative Gibbs energies for the $\mathrm{NH}$ isomers augments their contributions in the tautomeric mixture of $\mathbf{2} \mathbf{A P Y}^{+\bullet}$. The percentage contents of $\mathbf{2 A P Y 2} \mathbf{b}^{+\bullet}$ and $\mathbf{2 A P Y} 2 \mathbf{a}^{+\bullet}$ are considerably larger $\left(0.1\right.$ and $3 \cdot 10^{-4} \%$, respectively) than those in neutral $\mathbf{2 A P Y}\left(<1 \cdot 10^{-8} \%\right)$. They cannot be neglected in the tautomeric mixture of $\mathbf{2} \mathbf{A P Y} \mathbf{P}^{\mathbf{\bullet}}$. Quite a different situation takes place for the imine $\mathrm{CH}$ tautomers. The relative Gibbs energies increase to more than $50 \mathrm{kcal} \mathrm{mol}^{-1}$ for both isomers ( $\mathbf{a}$ and $\mathbf{b}$ ) of $\mathbf{2} \mathbf{A P Y} \mathbf{3}^{+\boldsymbol{\bullet}}$ and $\mathbf{2 A P Y}^{+\boldsymbol{\bullet}}$. Change of the configuration for the exo $=\mathrm{NH}$ group has a small effect on the relative Gibbs energies $\left(<3 \mathrm{kcal} \mathrm{mol}^{-1}\right)$. The percentage contents of the imine $\mathrm{CH}$ isomers are very low $\left(<1 \cdot 10^{-29} \%\right)$. As very rare isomers, they may be neglected in the tautomeric mixture of $\mathbf{2} \mathbf{A P Y}^{+}$.

In the case of 4-aminopyridine, one-electron oxidation also changes the DFT-stabilities of the amine $\mathbf{4 A P Y} \mathbf{1}^{+\bullet}$ and imine $\mathbf{4 A P Y 3}^{+\bullet}$ tautomers (Table 2) but in higher degree than for 2-aminopyridine (Table 1). Consequently, $\mathbf{4 A P Y}^{+\bullet}$, instead of $\mathbf{4 A P Y} \mathbf{1}^{+\bullet}$, seems to be the favored tautomer for the radical cation. Since the relative Gibbs energy between the two tautomers is not very large (ca. $2 \mathrm{kcal} \mathrm{mol}^{-1}$ ), they may dictate the composition of the tautomeric mixture (95.7 and $4.3 \%$, respectively). The relative Gibbs energies of the imine $\mathrm{CH}$ isomers 4APY2a/ $\mathbf{4 a}^{+\bullet}$ and 4APY2 $\mathbf{b} / \mathbf{4 b}^{+\bullet}$ are larger than $40 \mathrm{kcal} \mathrm{mol}^{-1}$ and they seem to not depend on the configuration of the exo $=\mathrm{NH}$ group. The two $\mathrm{CH}$ isomers may be neglected in the tautomeric mixture of $\mathbf{4} \mathbf{A} \mathbf{P Y} \mathbf{Y}^{+\bullet}$. Their percentage contents are exceptionally low $\left(<1 \cdot 10^{-28} \%\right)$.

One-electron reduction changes the tautomeric preference for both 2- and 4-aminopyridines. For reduced aminopyridines, the imine $\mathrm{CH}$ isomers $\mathbf{2 A P Y} \mathbf{4 a}^{-\bullet}$ and $\mathbf{4 A P Y 2 b}$ $\mathbf{4 b}^{-\bullet}$ with the labile proton at the endo $\mathrm{C} 3 / \mathrm{C} 5$ atom and with the imine $\mathrm{H}$ atom antiperiplanar to the $\mathrm{C} 3 / \mathrm{C} 5$ atom have the lowest energies at the B3LYP/6-311+G(d,p) level (Tables 1 and 2). The $\mathbf{2 A P Y} \mathbf{4} \mathbf{b}^{-\boldsymbol{\bullet}}$ and $\mathbf{4 A P Y} \mathbf{2} \mathbf{a} / \mathbf{4 a}^{-\boldsymbol{\bullet}}$ isomers with the imine $\mathrm{H}$ atom synperiplanar to the $\mathrm{C} 3 / \mathrm{C} 5$ atom possess 
Table 1 The DFT-calculated relative thermodynamic parameters $\left(\Delta E_{\mathrm{T}}, \Delta H_{\mathrm{T}}, T \Delta S_{\mathrm{T}}, \Delta G_{\mathrm{T}}\right.$, and $\left.\mathrm{p} K_{\mathrm{T}}\right)$ and the percentage contents $(x$ in \%) for the neutral isomers of 2APY and for its unpaired ions $\mathbf{2} \mathbf{A P Y}^{+\bullet}$ and $\mathbf{2} \mathbf{A P Y} \mathbf{P}^{-}$

${ }^{\mathrm{a}} \Delta$ ZPE included ${ }^{\mathrm{b}}$ In $\mathrm{kcal} \mathrm{mol}^{-1}$

${ }^{\mathrm{c}}$ At $298.15 \mathrm{~K}^{\mathrm{d}}$ Thermodynamic parameters relative to those for 2APY1 ${ }^{\mathrm{e}}$ Thermodynamic parameters relative to those for 2APY $1^{+\bullet}{ }^{\mathrm{f}}$ Thermodynamic parameters relative to those for $2 \mathrm{APY} 4 \mathrm{a}^{-0}$

\begin{tabular}{|c|c|c|c|c|c|c|c|}
\hline Isomer & Charge & $\Delta E_{\mathrm{T}}^{\mathrm{a}, \mathrm{b}}$ & $\Delta H_{\mathrm{T}}^{\mathrm{b}, \mathrm{c}}$ & $T \Delta S_{\mathrm{T}}^{\mathrm{b}, \mathrm{c}}$ & $\Delta G_{\mathrm{T}}^{\mathrm{b}, \mathrm{c}}$ & $\mathrm{p} K_{\mathrm{T}}^{\mathrm{c}}$ & $x$ \\
\hline \multicolumn{8}{|l|}{ a) neutral ${ }^{\mathrm{d}}$} \\
\hline 2APY1 & 0 & 0.0 & 0.0 & 0.0 & 0.0 & 0.0 & 100 \\
\hline 2APY2a & 0 & 16.7 & 16.7 & 0.0 & 16.7 & 12.2 & $6 \cdot 10^{-11}$ \\
\hline 2APY2b & 0 & 14.0 & 13.9 & 0.0 & 13.9 & 10.2 & $6 \cdot 10^{-9}$ \\
\hline 2APY3a & 0 & 29.2 & 29.2 & 0.4 & 28.8 & 21.1 & $8 \cdot 10^{-20}$ \\
\hline 2APY3b & 0 & 33.4 & 33.4 & 0.6 & 32.8 & 24.0 & $9 \cdot 10^{-23}$ \\
\hline 2APY4a & 0 & 30.7 & 30.7 & 0.4 & 30.4 & 22.2 & $6 \cdot 10^{-21}$ \\
\hline 2APY4b & 0 & 35.4 & 35.4 & 0.4 & 35.0 & 25.7 & $2 \cdot 10^{-24}$ \\
\hline \multicolumn{8}{|l|}{ b) oxidized ${ }^{\mathrm{e}}$} \\
\hline $2 \mathrm{APY}^{+\bullet}$ & 1 & 0.0 & 0.0 & 0.0 & 0.0 & 0.0 & 99.9 \\
\hline $2 \mathrm{APY} 2 \mathrm{a}^{+\bullet}$ & 1 & 7.4 & 7.4 & -0.2 & 7.5 & 5.5 & $3 \cdot 10^{-4}$ \\
\hline $2 \mathrm{APY} \mathrm{b}^{+\bullet}$ & 1 & 3.8 & 3.6 & -0.2 & 3.9 & 2.8 & 0.1 \\
\hline $2 \mathrm{APY}^{+\mathrm{a}^{+}}$ & 1 & 50.6 & 50.9 & 0.8 & 50.2 & 36.8 & $2 \cdot 10^{-35}$ \\
\hline $2 \mathrm{APY} \mathrm{b}^{+\bullet}$ & 1 & 52.0 & 52.5 & 1.2 & 51.2 & 37.6 & $3 \cdot 10^{-36}$ \\
\hline $2 \mathrm{APY}_{4} \mathrm{a}^{+\bullet}$ & 1 & 50.2 & 49.9 & -0.5 & 50.4 & 36.9 & $8 \cdot 10^{-30}$ \\
\hline $2 \mathrm{APY}_{4} \mathrm{~b}^{+\bullet}$ & 1 & 53.4 & 53.8 & 0.9 & 52.9 & 38.8 & $2 \cdot 10^{-37}$ \\
\hline \multicolumn{8}{|l|}{ c) reduced $^{\mathrm{f}}$} \\
\hline $2 \mathrm{APY}^{-}{ }^{-}$ & -1 & 3.9 & 4.1 & -0.1 & 4.2 & 3.1 & $8 \cdot 10^{-2}$ \\
\hline $2 \mathrm{APY} 2 \mathrm{a}^{-}$ & -1 & 9.4 & 9.7 & 0.2 & 9.5 & 7.0 & $1 \cdot 10^{-5}$ \\
\hline $2 \mathrm{APY} 2 \mathrm{~b}^{-\bullet}$ & -1 & 6.1 & 6.4 & 0.2 & 6.2 & 4.5 & $3 \cdot 10^{-3}$ \\
\hline $2 \mathrm{APY} 3 \mathrm{a}^{-\bullet}$ & -1 & 11.9 & 11.8 & -0.3 & 12.1 & 8.9 & $1 \cdot 10^{-9}$ \\
\hline $2 \mathrm{APY} 3 \mathrm{~b}^{-\bullet}$ & -1 & 15.5 & 15.4 & -0.3 & 15.8 & 11.5 & $3 \cdot 10^{-10}$ \\
\hline $2 \mathrm{APY} 4 \mathrm{a}^{-\bullet}$ & -1 & 0.0 & 0.0 & 0.0 & 0.0 & 0.0 & 99.9 \\
\hline $2 A P Y 4 b^{-\bullet}$ & -1 & 4.8 & 4.8 & 0.0 & 4.8 & 3.5 & $3 \cdot 10^{-2}$ \\
\hline
\end{tabular}

larger Gibbs energies than $\mathbf{2 A P Y} \mathbf{4 a}^{-\boldsymbol{\bullet}}$ and $\mathbf{4 A P Y} \mathbf{2 b} / \mathbf{4 b}^{-\bullet}$ by ca. 5 and $1 \mathrm{kcal} \mathrm{mol}^{-1}$, respectively. The other reduced tautomers have larger Gibbs energies than those of 2APY $4 \mathbf{a}^{-\bullet}$ and $\mathbf{4 A P Y 2} \mathbf{b} / \mathbf{4 b}^{-\bullet}$ by $4-16 \mathrm{kcal} \mathrm{mol}^{-1}$. The tautomeric mixture of $\mathbf{2} \mathbf{A} \mathbf{P} \mathbf{Y}^{-\bullet}$ seems to consist mainly of

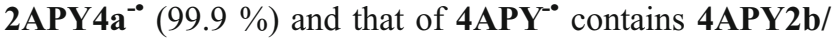
$\mathbf{4 b}^{-\bullet}$ and 4APY2a/4a $\mathbf{a}^{-\bullet}$ (86.8 and $13.2 \%$, respectively). The percentage contents of the other isomers are lower than $0.1 \%$.

If we consider solely the DFT-favored neutral and redox forms of 2- and 4-aminopyridines, the following scheme of the redox reactions can be drawn (Scheme 3 ). The percentage contents of the major amine and imine tautomers are also given in this scheme. Generally, the tautomeric preferences for aminopyridines are the same for the neutral and reduced forms. The neutral tautomeric mixtures of 2APY and 4APY contain mainly the amine tautomers (100\%), and those of $\mathbf{2} \mathbf{A P Y} \mathbf{P Y}^{\bullet}$ and $\mathbf{4} \mathbf{A P Y} \mathbf{Y}^{\bullet}$ consists of the major imine $\mathbf{C H}$ tautomers (99.9-100\%) and of the minor amine tautomers $(\leq 0.1 \%)$. Solely, the tautomeric preferences for the oxidized forms seem to be dependent on the positions of the exo and endo $\mathrm{N}$ atoms. The amine tautomer (99.9\%) is favored for $\mathbf{2} \mathbf{A} \mathbf{P Y} \mathbf{Y}^{+}$whereas the imine $\mathrm{NH}$ tautomer $(95.7 \%)$ dominates for $\mathbf{4 A P Y} \mathbf{P Y}^{+}$.
Since the relative energies between the major tautomers of the ionic forms of 4APY are only slightly larger than the error of the B3LYP method estimated for 2-hydroxypyridine/2hydroxypyridone (ca. $1 \mathrm{kcal} \mathrm{mol}^{-1}$ ) [38], the DFT results should be very carefully used for interpretation of oxidation and reduction reactions. A slight change of environment may change the relative energy values, and consequently, it may change the composition of the tautomeric mixture.

The relative entropy terms $\left(T \Delta S_{\mathrm{T}}\right)$ for the neutral and redox forms of 2- and 4-aminopyridines are not larger than $\pm 1 \mathrm{kcal} \mathrm{mol}^{-1}$. This may suggest that all tautomeric conversions are isoentropic in the gas phase and do not depend on the oxidation or reduction state of the molecule. Generally, there are not large structural changes during tautomerization. Some exceptions are those resulting from loss of the molecule planarity. The relative thermal corrections (from zero to $298.15 \mathrm{~K}$ ) are close to zero, and thus, $\Delta E_{\mathrm{T}} \approx \Delta H_{\mathrm{T}} \approx \Delta G_{\mathrm{T}}$. All these observations suggest that the relative thermodynamic parameters do not depend very much on temperature (thermal corrections and entropy terms cancel out), and thus the percentage contents of the same order of magnitude may be expected for individual tautomers in a jet- 
Table 2 The DFT-calculated relative thermodynamic parameters $\left(\Delta E_{\mathrm{T}}, \Delta H_{\mathrm{T}}, T \Delta S_{\mathrm{T}}, \Delta G_{\mathrm{T}}\right.$, and $\left.\mathrm{p} K_{\mathrm{T}}\right)$ and the percentage contents ( $\mathrm{x}$ in \%) for the neutral isomers of 4APY and for its unpaired ions $\mathbf{4} \mathbf{A P Y}^{+\bullet}$ and $4 \mathrm{APY}^{\circ}$
${ }^{\mathrm{a}} \Delta \mathrm{ZPE}$ included ${ }^{\mathrm{b}}$ In $\mathrm{kcal} \mathrm{mol}^{-1}$ ${ }^{c}$ At $298.15 \mathrm{~K}^{\mathrm{d}}$ Thermodynamic parameters relative to those for 4APY1 ${ }^{\mathrm{e}}$ Thermodynamic parameters relative to those for $\mathbf{4 A P Y 3}^{+\bullet}$

${ }^{\mathrm{f}}$ Thermodynamic parameters relative to those for $\mathbf{4 A P Y} \mathbf{2} b / \mathbf{4} b^{-\bullet}$

\begin{tabular}{|c|c|c|c|c|c|c|c|}
\hline Isomer & Charge & $\Delta E_{\mathrm{T}}^{\mathrm{a}, \mathrm{b}}$ & $\Delta H_{\mathrm{T}}^{\mathrm{b}, \mathrm{c}}$ & $T \Delta S_{\mathrm{T}}^{\mathrm{b}, \mathrm{c}}$ & $\Delta G_{\mathrm{T}}^{\mathrm{b}, \mathrm{c}}$ & $\mathrm{p} K_{\mathrm{T}}{ }^{\mathrm{c}}$ & $x$ \\
\hline \multicolumn{8}{|l|}{ a) neutral ${ }^{d}$} \\
\hline 4APY1 & 0 & 0.0 & 0.0 & 0.0 & 0.0 & 0.0 & 100 \\
\hline 4APY2a/4a & 0 & 30.9 & 31.0 & 0.6 & 30.4 & 22.3 & $5 \cdot 10^{-21}$ \\
\hline $4 A P Y 2 b / 4 b$ & 0 & 30.3 & 30.4 & 0.6 & 29.8 & 21.8 & $1 \cdot 10^{-20}$ \\
\hline 4APY3 & 0 & 16.5 & 16.5 & 0.1 & 16.4 & 12.0 & $9 \cdot 10^{-11}$ \\
\hline \multicolumn{8}{|l|}{ b) oxidized ${ }^{\mathrm{e}}$} \\
\hline 4APY1 $^{+\bullet}$ & 1 & 1.8 & 1.8 & -0.1 & 1.9 & 1.4 & 4.3 \\
\hline $4 \mathrm{APY} 2 \mathrm{a} / \mathbf{4 a}^{+\bullet}$ & 1 & 42.3 & 42.7 & 1.0 & 41.7 & 30.5 & $3 \cdot 10^{-29}$ \\
\hline $4 \mathrm{APY} 2 \mathrm{~b} / 4 \mathrm{~b}^{+\bullet}$ & 1 & 42.4 & 42.9 & 1.2 & 41.7 & 30.6 & $3 \cdot 10^{-29}$ \\
\hline $4 \mathrm{APY}^{+\bullet}$ & 1 & 0.0 & 0.0 & 0.0 & 0.0 & 0.0 & 95.7 \\
\hline \multicolumn{8}{|l|}{ c) reduced $^{\mathrm{f}}$} \\
\hline 4APY1 ${ }^{-\bullet}$ & -1 & 4.1 & 4.0 & -0.5 & 4.6 & 3.3 & $4 \cdot 10^{-2}$ \\
\hline 4APY2a/4a & -1 & 1.1 & 1.1 & -0.1 & 1.2 & 0.9 & 13.2 \\
\hline $4 \mathrm{APY} 2 \mathrm{~b} / 4 \mathrm{~b}^{-\bullet}$ & -1 & 0.0 & 0.0 & 0.0 & 0.0 & 0.0 & 86.8 \\
\hline 4APY3 ${ }^{-\circ}$ & -1 & 12.2 & 11.8 & -1.0 & 12.9 & 9.4 & $4 \cdot 10^{-8}$ \\
\hline
\end{tabular}

cooled experiments. Very low thermal corrections and entropy terms have been also observed for aniline [6] and 4-aminopyrimidine [7].

\section{Oxidation and reduction energies}

For each isomer of $\mathbf{2 A P Y}$ and $\mathbf{4 A P Y}$, thermodynamic parameters of oxidation $\left(\Delta E_{\mathrm{ox}}, \Delta H_{\mathrm{ox}}, T \Delta S_{\mathrm{ox}}\right.$, and $\left.\Delta G_{\text {ox }}\right)$ and reduction $\left(\Delta E_{\text {red }}, \Delta H_{\text {red }}, T \Delta S_{\text {red }}\right.$, and $\left.\Delta G_{\text {red }}\right)$ were estimated at the DFT(B3LYP)/6-311+G(d,p) level. They were calculated as differences between the corresponding parameters for the charged and neutral forms. First perusal of these parameters indicates that one-electron oxidation is a very endothermic process (Table 3). The lowest energies (173-174 kcal mol${ }^{-1}$ ) are needed for the imine $\mathrm{NH}$ tautomers, and the largest energies (201-205 kcal mol${ }^{-1}$ ) for the imine $\mathrm{CH}$ tautomers. For the amine tautomers, the oxidation Gibbs energies $\left(\Delta G_{\text {ox }} 183-192 \mathrm{kcal} \mathrm{mol}^{-1}\right)$ are between those for the imine $\mathrm{NH}$ and $\mathrm{CH}$ tautomers. Change of the configuration of the imine $\mathrm{H}$ atom in structures $\mathbf{a}$ and b has small effect on the $\Delta G_{\mathrm{ox}}$ values $\left(<3 \mathrm{kcal} \mathrm{mol}^{-1}\right)$. Interestingly, the literature ionization energies for 2aminopyridine (8.5 eV [52], $1 \mathrm{eV}=23.06037 \mathrm{kcal}$ $\left.\mathrm{mol}^{-1}\right)$ and for 4-aminopyridine $(8.8 \mathrm{eV}$ [52]) are of the same order of magnitude as the DFT estimated energies of oxidation.

One-electron reduction is a more favorable process than one-electron oxidation. Comparison of the DFT calculated thermodynamic parameters for the reduced and neutral tautomers of $\mathbf{2 A P Y}$ and $\mathbf{4 A P Y}$ shows that one-electron reduction requires less than $20 \mathrm{kcal} \mathrm{mol}^{-1}$ (Table 4). For the imine $\mathrm{CH}$ isomers, the reduction Gibbs energies $\left(\Delta G_{\mathrm{red}}\right)$ are even negative, indicating that aminopyridines may take spontaneously one electron from a reducing agent. They may be more easily transformed to the reduced forms than the imine $\mathrm{NH}$ and amine tautomers for which the $\Delta G_{\text {red }}$ values are positive. This trend confirms preference of the imine $\mathrm{CH}$ tautomers in the tautomeric mixtures of $\mathbf{2} \mathbf{A P Y}^{\bullet}$ and $\mathbf{4} \mathbf{A P Y} \mathbf{P Y}^{*}$. Change of the
Scheme 3 The tautomeric preferences for the redox forms of aminopyridines estimated at the DFT(B3LYP)/6-311+G(d,p) level

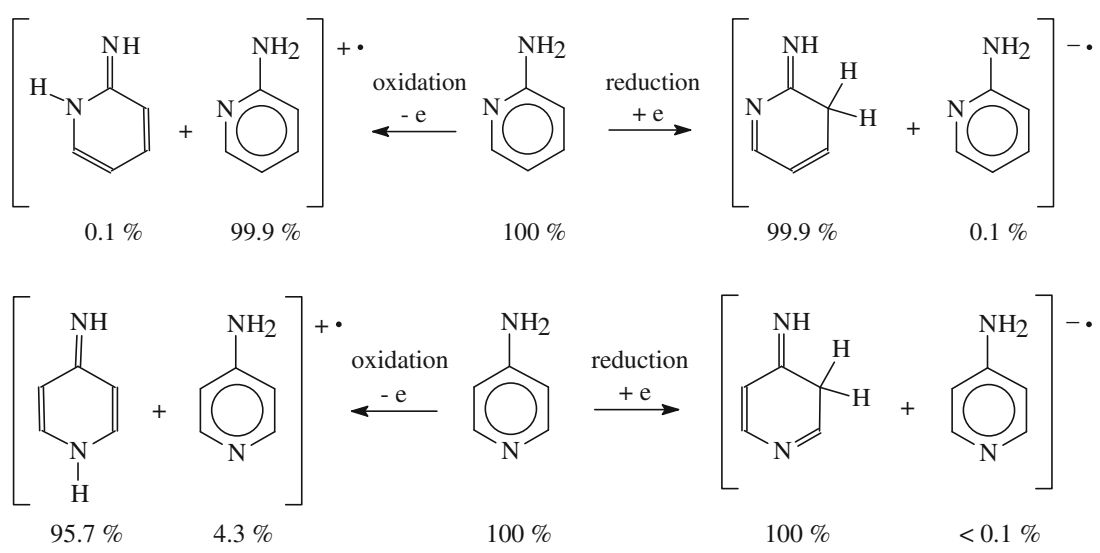


Table 3 The DFT-estimated energies of oxidation ( $\Delta E_{\mathrm{ox}}, \Delta H_{\mathrm{ox}}$, and $\left.\Delta G_{\mathrm{ox}}\right)$ and entropy terms $\left(T \Delta S_{\mathrm{ox}}\right)$ for individual isomers of 2APY and 4APY

\begin{tabular}{|c|c|c|c|c|}
\hline Oxidation & $\Delta E_{\mathrm{ox}}^{\mathrm{a}, \mathrm{b}}$ & $\Delta H_{\mathrm{ox}}^{\mathrm{b}, \mathrm{c}}$ & $T \Delta S_{\mathrm{ox}}^{\mathrm{b}, \mathrm{c}}$ & $\Delta G_{\mathrm{ox}}^{\mathrm{b}, \mathrm{c}}$ \\
\hline $\begin{array}{c}\text { 2APY1 }-\mathrm{e} \\
\text { 2APY1 }^{+\bullet}\end{array}$ & 183.7 & 183.7 & 0.4 & 183.3 \\
\hline$\underset{2 \mathrm{AAPY} 2 \mathrm{a}^{+\bullet}}{2 \mathrm{APY}} \rightarrow$ & 174.4 & 174.4 & 0.2 & 174.1 \\
\hline $\begin{array}{c}\text { 2APY2b }-\mathrm{e} \rightarrow \\
2 \mathrm{APY} 2 \mathrm{~b}^{+\bullet}\end{array}$ & 173.5 & 173.4 & 0.2 & 173.2 \\
\hline$\underset{2 \mathrm{APY}}{2 \mathrm{APY} 3 \mathrm{a}^{+\bullet}} \rightarrow$ & 205.2 & 205.4 & 0.7 & 204.7 \\
\hline $\begin{array}{c}2 \mathrm{APY} 3 \mathrm{~b}-\mathrm{e} \\
\mathbf{2 A P Y}^{+\bullet}\end{array}$ & 202.3 & 202.8 & 1.0 & 201.8 \\
\hline $\begin{array}{c}\text { 2APY4a }-\mathrm{e} \\
2 \mathrm{APY} 4 \mathrm{a}^{+\bullet}\end{array}$ & 203.3 & 203.7 & 1.2 & 202.5 \\
\hline $\begin{array}{c}2 \mathrm{APY} 4 \mathrm{~b}-\mathrm{e} \rightarrow \\
2 \mathrm{APY} 4 \mathrm{~b}^{+\bullet}\end{array}$ & 201.8 & 202.1 & 0.9 & 201.2 \\
\hline $\begin{array}{l}\text { 4APY1 }-\mathrm{e} \rightarrow \\
\text { 4APY1 }^{+\bullet}\end{array}$ & 192.0 & 192.0 & 0.5 & 191.6 \\
\hline $\begin{array}{c}\text { 4APY2a }-\mathrm{e} \rightarrow \\
{\text { 4APY } 2 \mathrm{a}^{+\bullet}}^{\text {A }}\end{array}$ & 201.2 & 201.4 & 0.6 & 200.8 \\
\hline $\begin{array}{c}\text { 4APY2b }-\mathrm{e} \rightarrow \\
\text { 4APY2 }{ }^{+\bullet}\end{array}$ & 201.9 & 202.2 & 0.8 & 201.4 \\
\hline $\begin{array}{c}\text { 4APY3 }-\mathrm{e} \rightarrow \\
\text { 4APY }^{+\bullet}\end{array}$ & 173.4 & 173.2 & 0.2 & 173.1 \\
\hline
\end{tabular}

${ }^{\mathrm{a}} \triangle \mathrm{ZPE}$ included ${ }^{\mathrm{b}} \mathrm{In} \mathrm{kcal} \mathrm{mol}^{-1} \mathrm{c}$ At $298.15 \mathrm{~K}$

position of the imine $\mathrm{H}$ atom has no important effect on the $\Delta G_{\text {red }}$ values $\left(<1 \mathrm{kcal} \mathrm{mol}^{-1}\right)$. There are no experimental data

Table 4 The DFT-estimated energies of reduction $\left(\Delta E_{\text {red }}, \Delta H_{\text {red }}\right.$, and $\left.\Delta G_{\text {red }}\right)$ and entropy terms $\left(T \Delta S_{\text {red }}\right)$ for individual isomers of $2 \mathbf{A P Y}$ and 4APY

\begin{tabular}{|c|c|c|c|c|}
\hline Reduction & $\Delta E_{\text {red }}{ }^{\mathrm{a}, \mathrm{b}}$ & $\Delta H_{\mathrm{red}}^{\mathrm{b}, \mathrm{c}}$ & $T \Delta S_{\text {red }} \mathrm{b}, \mathrm{c}$ & $\Delta G_{\text {red }} \mathrm{b}$, \\
\hline $\begin{array}{l}\text { 2APY1 }-\mathrm{e} \rightarrow \\
\text { 2APY1- }^{-}\end{array}$ & 17.6 & 16.1 & 1.0 & 15.1 \\
\hline $\begin{array}{c}\text { 2APY2a }-\mathrm{e} \rightarrow \\
2 \text { 2APY2a- }\end{array}$ & 4.5 & 5.0 & 1.3 & 3.7 \\
\hline $\begin{array}{c}\text { 2APY2b }-\mathrm{e} \rightarrow \\
2 \mathrm{APY} 2 \mathrm{~b}^{-0}\end{array}$ & 3.9 & 4.5 & 1.3 & 3.2 \\
\hline $\begin{array}{c}\text { 2APY3a }-\mathrm{e} \rightarrow \\
2 \text { 2APY3a- }\end{array}$ & -5.5 & -5.4 & 0.4 & -5.8 \\
\hline $\begin{array}{c}2 \mathrm{APY} 3 \mathrm{~b}-\mathrm{e} \\
\mathbf{2 A P Y} 3 \mathrm{~b}^{-\bullet}\end{array}$ & -6.1 & -6.0 & 0.1 & -6.1 \\
\hline $\begin{array}{c}\text { 2APY4a }-\mathrm{e} \rightarrow \\
2 \mathrm{APY} 4 \mathrm{a}^{-\bullet}\end{array}$ & -18.9 & -18.7 & 0.7 & -19.5 \\
\hline $\begin{array}{c}\text { 2APY } 4 b-\mathrm{e} \rightarrow \\
2 \mathrm{APY} 4 \mathrm{~b}^{-0}\end{array}$ & -18.8 & -18.6 & 0.8 & -19.4 \\
\hline $\begin{array}{l}\text { 4APY1 }-\mathrm{e} \rightarrow \\
\text { 4APY1 }{ }^{-0}\end{array}$ & 16.7 & 16.8 & 0.7 & 16.1 \\
\hline $\begin{array}{l}\text { 4APY2a }-\mathrm{e} \rightarrow \\
\text { 4APY2a- }\end{array}$ & -17.2 & -17.1 & 0.5 & -17.6 \\
\hline $\begin{array}{c}\text { 4APY2b }-\mathrm{e} \rightarrow \\
{\text { 4APY } 2 \mathrm{~b}^{-}}^{-0}\end{array}$ & -17.7 & -17.6 & 0.6 & -18.2 \\
\hline $\begin{array}{c}\text { 4APY3 }-\mathrm{e} \rightarrow \\
\text { 4APY3 }^{-0}\end{array}$ & 8.3 & 8.1 & 0.1 & 8.0 \\
\hline
\end{tabular}

${ }^{\mathrm{a}} \triangle \mathrm{ZPE}$ included ${ }^{\mathrm{b}}$ In kcal mol ${ }^{-1 \mathrm{c}}$ At $298.15 \mathrm{~K}$ in the literature [53] for the electron affinity of 2APY and 4APY and no comparison can be made.

Similar to the proton-transfer interconversions, the entropy terms for both one-electron oxidation $\left(T \Delta S_{\mathrm{ox}}\right)$ and one-electron reduction $\left(T \Delta S_{\text {red }}\right)$ are not very large $\left(\leq 1.3 \mathrm{kcal} \mathrm{mol}^{-1}\right)$. This suggests that the electron-transfer processes (electron-loss and electron-gain) are isoentropic in the gas phase for aminopyridines. The relative thermal corrections are also close to zero, and thus, $\Delta E_{\mathrm{ox}} \approx \Delta H_{\mathrm{ox}} \approx$ $\Delta G_{\mathrm{ox}}$ and $\Delta E_{\mathrm{red}} \approx \Delta H_{\mathrm{red}} \approx \Delta G_{\text {red. }}$. If we consider solely the most favored neutral and redox forms of aminopyridines and the favored oxidation and reduction processes (Scheme 3), the following DFT Gibbs energies are found: $183 \mathrm{kcal} \mathrm{mol}^{-1}$ for $\mathbf{2} \mathbf{A P Y}-\mathrm{e} \rightarrow \mathbf{2} \mathbf{A P Y}^{+\boldsymbol{*}}, 190 \mathrm{kcal} \mathrm{mol}^{-1}$ for $\mathbf{4 A P Y}-\mathrm{e} \rightarrow \mathbf{4} \mathbf{A P Y}^{+\bullet}, 11 \mathrm{kcal} \mathrm{mol}^{-1}$ for $\mathbf{2} \mathbf{A P Y}-\mathrm{e} \rightarrow \mathbf{2} \mathbf{A P Y}^{\bullet}$, and $12 \mathrm{kcal} \mathrm{mol}^{-1}$ for $\mathbf{4 A P Y}-\mathrm{e} \rightarrow \mathbf{4} \mathbf{A P Y} \mathbf{P Y}^{-}$. The oxidation and reduction reactions for 4APY requires more energy (by 7 and $1 \mathrm{kcal} \mathrm{mol}^{-1}$, respectively) than those for $\mathbf{2 A P Y}$. Larger difference for the oxidation reaction results from the difference in the tautomeric preferences, $\mathbf{2} \mathbf{A P Y} \mathbf{1}^{+\boldsymbol{\bullet}}$ and $\mathbf{4} \mathbf{A P Y} \mathbf{3}^{+\boldsymbol{\bullet}}$. Interestingly, the literature ionization energy difference for $\mathbf{2 A P Y}$ and 4APY is also equal to $7 \mathrm{kcal} \mathrm{mol}^{-1}(0.3 \mathrm{eV} \mathrm{[52]).}$

\section{N-aza-effects}

The amino derivatives of azines studied here (2APY and 4APY) and previously (4APM) can be considered as N-aza derivatives of aniline (AN). All of them exhibit prototropic tautomerism (Scheme 4). Such kind of treatment of azaanilines gives the possibility to estimate effects of the $\mathrm{N}$-aza group in different position of aniline, 2-N, 4-N and 2,4- $\mathrm{N}_{2}$. In this paper, we analyzed the $\mathrm{N}$-aza effects on $\pi$-electron delocalization, intramolecular proton-transfer processes

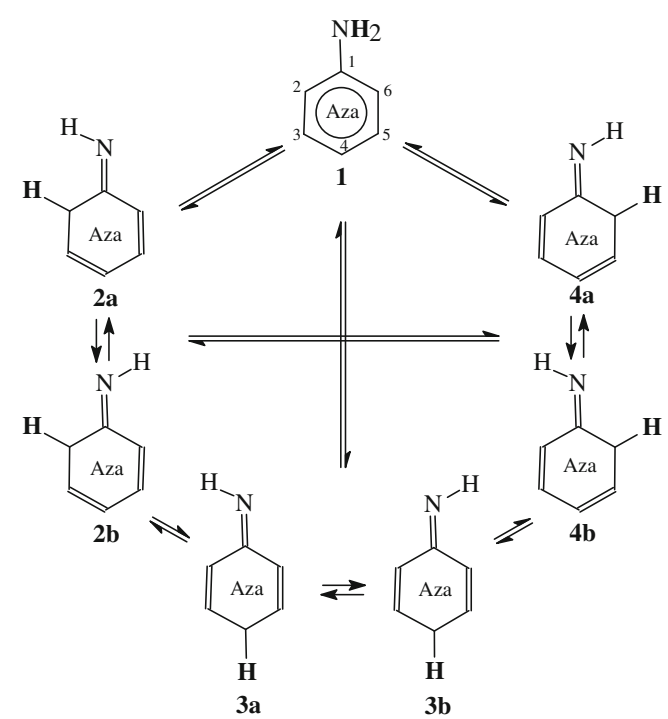

Scheme 4 Tautomeric equilibria for azaanilines (labile proton marked in bold) 
(prototropy) and redox reactions for azaanilines. We compared the corresponding parameters (HOMED, $\mathrm{p} K_{\mathrm{T}}, \Delta G_{\mathrm{ox}}$, and $\Delta G_{\text {red }}$ ) calculated at the same level of theory, DFT (B3LYP) $/ 6-311+G(d, p)$, i.e., those reported in refs [6] and [7] and also those given here in Figs. 4 and 5 and Tables 1, 2,3 , and 4 .

Table 5 summarizes the $\mathrm{N}$-aza effects on the HOMED indices estimated for the ring (six bonds) when going from similar isomers of aniline (AN) without the $\mathrm{N}$-aza group to those of 2-aminopyridine (2APY) and 4-aminopyridine (4APY) with one N-aza group in 2- and 4-position, respectively, vis-à-vis the amine group, and to those of 4aminopyrimidine (4APM) with two N-aza groups in 2- and 4-position. The comparison shows that for the amine tautomer 1, each N-aza group decreases the HOMED indices in higher degree for the anionic than neutral forms (by 0.09 and 0.01 units, respectively), while it increases them for the cationic forms (by ca. 0.02 units). The $\mathrm{N}$-aza effects seem to be additive when going from AN1 to 2APY1, 4APY1, and 4APM1.

Table 5 The $\mathrm{N}$-aza effects $(\delta)$ on the HOMED indices estimated for the ring (six bonds) in individual tautomers of azaanilines

\begin{tabular}{|c|c|c|c|c|}
\hline Isomer & Charge & $\begin{array}{l}\delta \text { HOMED } \\
(2-\mathrm{N})\end{array}$ & $\begin{array}{l}\delta \text { HOMED } \\
(4-\mathrm{N})\end{array}$ & $\begin{array}{l}\delta \text { HOMED } \\
\left(2,4-\mathrm{N}_{2}\right)\end{array}$ \\
\hline \multirow[t]{3}{*}{$\mathbf{1}\left(\mathrm{NH}_{2}\right)$} & 0 & -0.004 & -0.002 & -0.007 \\
\hline & 1 & 0.003 & 0.021 & 0.024 \\
\hline & -1 & -0.071 & -0.011 & -0.090 \\
\hline \multirow[t]{3}{*}{ 2a $(\mathrm{NH})$} & 0 & - & -0.030 & - \\
\hline & 1 & - & 0.011 & - \\
\hline & -1 & - & -0.002 & - \\
\hline \multirow[t]{3}{*}{$\mathbf{2 b}(\mathrm{NH})$} & 0 & - & -0.095 & - \\
\hline & 1 & - & 0.011 & - \\
\hline & -1 & - & -0.011 & - \\
\hline \multirow[t]{3}{*}{ 3a $(\mathrm{NH})$} & 0 & -0.080 & - & - \\
\hline & 1 & -0.019 & - & - \\
\hline & -1 & -0.043 & - & - \\
\hline \multirow[t]{3}{*}{$\mathbf{3 b}(\mathrm{NH})$} & 0 & -0.081 & - & - \\
\hline & 1 & -0.015 & - & - \\
\hline & -1 & -0.047 & - & - \\
\hline \multirow[t]{3}{*}{ 3a $(\mathrm{CH})$} & 0 & -0.057 & - & - \\
\hline & 1 & -0.011 & - & - \\
\hline & -1 & 0.021 & - & - \\
\hline \multirow[t]{3}{*}{$\mathbf{3 b}(\mathrm{CH})$} & 0 & -0.061 & - & - \\
\hline & 1 & 0.042 & - & - \\
\hline & -1 & -0.028 & - & - \\
\hline \multirow[t]{3}{*}{$\mathbf{4 a}(\mathrm{CH})$} & 0 & -0.029 & 0.019 & -0.183 \\
\hline & 1 & -0.470 & 0.083 & -0.564 \\
\hline & -1 & -0.022 & 0.028 & 0.000 \\
\hline \multirow[t]{3}{*}{$4 \mathbf{b}(\mathrm{CH})$} & 0 & -0.019 & -0.011 & -0.038 \\
\hline & 1 & -0.014 & -0.028 & -0.589 \\
\hline & -1 & 0.010 & 0.030 & 0.067 \\
\hline
\end{tabular}

For the neutral and ionic imine NH tautomers $\mathbf{2}$ and $\mathbf{3}$ in 4APM, the additional $\mathrm{N}$-aza group diminishes the HOMED indices in comparison to $\mathbf{2 A P Y}$ and $\mathbf{4 A P Y}$ (by less than 0.1 units). Some exceptions are the cationic isomers $\mathbf{2 a}$ and $\mathbf{2} \mathbf{b}$, for which the HOMED indices slightly augment (by 0.01 units). The HOMED indices also decease for the neutral and cationic imine $\mathrm{CH}$ tautomer 4 . Larger effects take place for the cationic forms ( $>0.5$ units) than for the neutral forms $(<0.2$ units). Some exceptions are the anionic forms, the HOMED indices slightly increase for $\mathbf{4 b}$ (by 0.07 units), however, for 4a the total effect of the two $\mathrm{N}$-aza groups is equal to zero because one $\mathrm{N}$-aza group decreases and the other $\mathrm{N}$-aza group increases the HOMED index in almost similar degree. In the case of the imine $\mathrm{CH}$ tautomer $\mathbf{3}$, the $\mathrm{N}$-aza group in 2-position (when going from $\mathbf{A N}$ to $\mathbf{2 A P Y}$ ) changes the HOMED indices by less than \pm 0.06 units. However, all these variations of the HOMED indices for tautomers of azaanilines do not change the general trend of $\pi$-electron delocalization: the amine and imine $\mathrm{NH}$ tautomers are more delocalized than the imine $\mathrm{CH}$ ones.

Comparison of the $\mathrm{p} K_{\mathrm{T}}$ values estimated for AN, 2APY, 4APY, and 4APM gives some information on the effects of the N-aza group(s) in 2-, 4- and 2,4-positions (Table 6). Generally, the 2-N-aza group increases the $\mathrm{p} K_{\mathrm{T}}$ values for both the $\mathrm{NH}_{2} \rightarrow \mathrm{CH}$ and $\mathrm{NH}_{2} \rightarrow \mathrm{NH}$ conversions $\left(\delta 0-7 \mathrm{p} K_{\mathrm{T}}\right.$ units) in the neutral and ionic forms of azaanilines. The 4-N-aza group has considerably smaller effect $\left(\delta 0- \pm 2 \mathrm{p} K_{\mathrm{T}}\right.$ units). It slightly increases the $\mathrm{p} K_{\mathrm{T}}$ values for the neutral and reduced $\mathrm{NH}_{2} \rightarrow$ $\mathrm{CH}$ conversions, and it decreases them for the $\mathrm{NH}_{2} \rightarrow \mathrm{NH}$ conversions. The effect of the two $\mathrm{N}$-aza groups seems to be additive only for the neutral forms.

Independent on the position in the ring, the $\mathrm{N}$-aza group increases the oxidation Gibbs energies (Table 7) and it decreases the reduction Gibbs energies (Table 8). For example, when going from aniline to aminopyridines and 4aminopyrimidine, the oxidation reaction for the amine tautomer 2APY1, 4APY1 and 4APM1 requires more energy than that for AN1 (by 10, 18, and $28 \mathrm{kcal} \mathrm{mol}^{-1}$, respectively), whereas lower energy (by 7, 6, and $12 \mathrm{kcal} \mathrm{mol}^{-1}$, respectively) is sufficient for the reduction reaction. The effects of the two N-aza groups included in the ring of 4APM1 seem to be additive.

\section{Conclusions}

DFT studies performed for all possible amine and imine tautomers of neutral aminopyridines and its unpaired ions show interesting changes of the tautomeric preferences. Solely for 2-aminopyridine, aromaticity seems to dictate the tautomeric preferences for the neutral and oxidized forms. The amine tautomer $\mathbf{2 A P Y} \mathbf{1}^{+\bullet}$ predominates for the oxidized tautomeric mixture of 2-aminopyridine, similarly 
Table 6 The $\mathrm{N}$-aza effects $(\delta)$ on the $\mathrm{p} K_{\mathrm{T}}$ values estimated for azaanilines

\begin{tabular}{|c|c|c|c|c|}
\hline Conversion & Tautomers & $\begin{array}{l}\delta \mathrm{p} K_{\mathrm{T}} \\
(2-\mathrm{N})\end{array}$ & $\begin{array}{l}\delta \mathrm{p} K_{\mathrm{T}} \\
(4-\mathrm{N})\end{array}$ & $\begin{array}{l}\delta \mathrm{p} K_{\mathrm{T}} \\
\left(2,4-\mathrm{N}_{2}\right)\end{array}$ \\
\hline $1 \rightarrow 2 \mathrm{a}$ & \multirow[t]{6}{*}{$\mathrm{NH}_{2} \rightarrow \mathrm{CH}$} & - & 1.5 & - \\
\hline $1 \rightarrow 2 \mathrm{~b}$ & & - & 1.1 & - \\
\hline $1 \rightarrow 3 \mathrm{a}$ & & 1.7 & - & - \\
\hline $1 \rightarrow 3 b$ & & 4.6 & - & - \\
\hline $1 \rightarrow 4 \mathrm{a}$ & & 4.9 & 1.5 & 6.2 \\
\hline $1 \rightarrow 4 b$ & & 1.5 & 1.1 & 2.9 \\
\hline $1 \rightarrow 2 a$ & \multirow[t]{4}{*}{$\mathrm{NH}_{2} \rightarrow \mathrm{NH}$} & - & -0.4 & - \\
\hline $1 \rightarrow 2 b$ & & - & -0.5 & - \\
\hline $1 \rightarrow 3 a$ & & 1.3 & - & - \\
\hline $1 \rightarrow 3 b$ & & 4.2 & - & - \\
\hline $\mathbf{1}^{+\bullet} \rightarrow \mathbf{2}^{\mathrm{a}^{\bullet}}$ & \multirow[t]{6}{*}{$\mathrm{NH}_{2} \rightarrow \mathrm{CH}$} & - & -2.4 & - \\
\hline $1^{+\bullet} \rightarrow 2 b^{+\bullet}$ & & - & -2.4 & - \\
\hline $\mathbf{1}^{+\bullet} \rightarrow 3 \mathrm{a}^{+\bullet}$ & & 1.7 & - & - \\
\hline $1^{+\bullet} \rightarrow 3 b^{+\bullet}$ & & 2.5 & - & - \\
\hline $1^{+\bullet} \rightarrow 4 a^{+\bullet}$ & & 7.3 & -2.4 & 0.1 \\
\hline $1^{+\bullet} \rightarrow 4 b^{+\bullet}$ & & 5.3 & -2.4 & -0.5 \\
\hline $\mathbf{1}^{+\bullet} \rightarrow \mathbf{2}^{\mathrm{a}^{\bullet}}$ & \multirow[t]{4}{*}{$\mathrm{NH}_{2} \rightarrow \mathrm{NH}$} & - & -1.9 & - \\
\hline $1^{+\bullet} \rightarrow 2 b^{+\bullet}$ & & - & -1.7 & - \\
\hline $\mathbf{1}^{+\bullet} \rightarrow 3 \mathrm{a}^{+\bullet}$ & & 2.7 & - & - \\
\hline $\mathbf{1}^{+\bullet} \rightarrow 3 \mathrm{~b}^{+\bullet}$ & & 6.0 & - & - \\
\hline $\mathbf{1}^{-\bullet} \rightarrow 2 \mathrm{a}^{-\bullet}$ & \multirow[t]{6}{*}{$\mathrm{NH}_{2} \rightarrow \mathrm{CH}$} & - & 0.1 & - \\
\hline $1^{-\bullet} \rightarrow 2 b^{-\bullet}$ & & - & 0.1 & - \\
\hline $1^{-\bullet} \rightarrow 3 \mathrm{a}^{-\bullet}$ & & 2.4 & - & - \\
\hline $1^{-\bullet} \rightarrow 3 b^{-\bullet}$ & & 5.0 & - & - \\
\hline $1^{-\bullet} \rightarrow 4 a^{-\bullet}$ & & 2.9 & 0.1 & 2.3 \\
\hline $1^{-\bullet} \rightarrow 4 b^{-\bullet}$ & & 0.3 & 0.1 & -0.2 \\
\hline $1^{-\bullet} \rightarrow 2 \mathrm{a}^{-\bullet}$ & \multirow[t]{4}{*}{$\mathrm{NH}_{2} \rightarrow \mathrm{NH}$} & - & -0.5 & - \\
\hline $1^{-\bullet} \rightarrow 2 b^{-\bullet}$ & & - & -0.4 & - \\
\hline $\mathbf{1}^{-\bullet} \rightarrow 3 \mathrm{a}^{-\bullet}$ & & 4.4 & - & - \\
\hline $1^{-\bullet} \rightarrow 3 b^{-\bullet}$ & & 7.1 & - & - \\
\hline
\end{tabular}

Table 7 The $\mathrm{N}$-aza effects $(\delta)$ on the $\Delta G_{\mathrm{ox}}$ values estimated for azaanilines

\begin{tabular}{lllll}
\hline Reaction & Tautomer & $\delta G_{\text {ox }}(2-\mathrm{N})$ & $\delta G_{\text {ox }}(4-\mathrm{N})$ & $\delta G_{\text {ox }}\left(2,4-\mathrm{N}_{2}\right)$ \\
\hline $\mathbf{1 \rightarrow \mathbf { 1 } ^ { + \bullet }}$ & $\mathrm{NH}_{2}$ & 9.6 & 17.9 & 27.9 \\
$\mathbf{2} \mathbf{a} \rightarrow \mathbf{2 a}^{+\bullet}$ & $\mathrm{NH}$ & - & 16.2 & - \\
$\mathbf{2} \mathbf{b} \rightarrow \mathbf{2 b}^{+\bullet}$ & $\mathrm{NH}$ & - & 16.6 & - \\
$\mathbf{3 a} \rightarrow \mathbf{3 a}^{+\bullet}$ & $\mathrm{NH}$ & 12.1 & - & - \\
$\mathbf{3 b} \rightarrow \mathbf{3 b}^{+\bullet}$ & $\mathrm{NH}$ & 12.3 & - & - \\
$\mathbf{3 a} \rightarrow \mathbf{3 a}^{+\bullet}$ & $\mathrm{CH}$ & 9.5 & - & - \\
$\mathbf{3 b} \rightarrow \mathbf{3 b}^{+\bullet}$ & $\mathrm{CH}$ & 6.6 & - & - \\
$\mathbf{4 a} \rightarrow \mathbf{4 a}^{+\bullet}$ & $\mathrm{CH}$ & 12.9 & 12.5 & 19.6 \\
$\mathbf{4 b \rightarrow \mathbf { b }} \mathbf{b}^{+\bullet}$ & $\mathrm{CH}$ & 13.8 & 12.7 & 23.1 \\
\hline
\end{tabular}

Table 8 The $\mathrm{N}$-aza effects $(\delta)$ on the $\Delta G_{\text {red }}$ values estimated for azaanilines

\begin{tabular}{lllll}
\hline Reaction & Tautomer & $\delta G_{\text {red }}(2-\mathrm{N})$ & $\delta G_{\text {red }}(4-\mathrm{N})$ & $\delta G_{\text {red }}\left(2,4-\mathrm{N}_{2}\right)$ \\
\hline $\mathbf{1} \rightarrow \mathbf{1}^{-\bullet}$ & $\mathrm{NH}_{2}$ & -6.7 & -5.7 & -12.0 \\
$\mathbf{2} \mathbf{a} \rightarrow \mathbf{2 a}^{-\bullet}$ & $\mathrm{NH}$ & - & -5.4 & - \\
$\mathbf{2} \mathbf{b} \rightarrow \mathbf{2} \mathbf{b}^{-}$ & $\mathrm{NH}$ & - & -5.2 & - \\
$\mathbf{3 a} \rightarrow \mathbf{3 a}^{-\bullet}$ & $\mathrm{NH}$ & -2.0 & - & - \\
$\mathbf{3 b} \rightarrow \mathbf{3} \mathbf{b}^{-\bullet}$ & $\mathrm{NH}$ & -2.2 & - & - \\
$\mathbf{3 a} \rightarrow \mathbf{3 a}^{-\bullet}$ & $\mathrm{CH}$ & -5.8 & - & - \\
$\mathbf{3 b} \rightarrow \mathbf{3} \mathbf{b}^{-}$ & $\mathrm{CH}$ & -6.1 & - & - \\
$\mathbf{4 a} \rightarrow \mathbf{4} \mathbf{a}^{-\bullet}$ & $\mathrm{CH}$ & -9.4 & -7.6 & -17.1 \\
$\mathbf{4 b} \rightarrow \mathbf{4} \mathbf{b}^{-\bullet}$ & $\mathrm{CH}$ & -8.5 & -7.2 & -16.2 \\
\hline
\end{tabular}

as 2APY1 for the neutral molecule. However, one-electron oxidation changes the composition of the tautomeric mixture. The neutral tautomeric mixture consists mainly of 2APY1 (100\%), whereas the oxidized tautomeric mixture contains at least two tautomers: $\mathbf{2 A P Y} \mathbf{1}^{\mathbf{*}}(99.9 \%)$ and $\mathbf{2 A P Y 2}^{+\bullet}(0.1 \%)$. For comparison, lack of the $\mathrm{N}$-aza group in aniline totally favors AN1 (100\%) and $\mathbf{A N 1}{ }^{+\bullet}(100 \%)$ for the neutral and oxidized tautomeric mixture [6].

In the case of 4-aminopyridine, one-electron oxidation changes the relative stabilities of the unpaired cations containing the labile proton at the $\mathrm{N}$ atom. For the neutral tautomeric mixture, 4APY1 is favored (100 \%), whereas $\mathbf{4 A P Y 3 ^ { + \bullet }}$ $(95.7 \%)$ seems to predominate over $\mathbf{4} \mathbf{A P Y} \mathbf{1}^{+\bullet}(4.3 \%)$ for the oxidized tautomeric mixture. Additional N-aza group in 2position for 4-aminopyrimidine changes the relation between the stabilities of the amine and imine $\mathrm{NH}$ tautomers, and 4APM1 $^{+\bullet}(88.3 \%)$ predominates over 4APM2 $^{+\bullet}(7.3 \%)$ and $\mathbf{A A P M 3}^{+\bullet}(4.4 \%)$ for the oxidized tautomeric mixtures [7]. The imine $\mathrm{CH}$ tautomers may be considered as very rare forms for both neutral and oxidized aminoazines.

The orders of stabilities for the unpaired anion isomers are completely reversed for aminopyridines but similar to those for aniline [6] and 4-aminopyrimidine [7]. The imine $\mathrm{CH}$ tautomers are favored for the reduced aminoazines. The tautomeric mixtures of 2- and 4-aminopyridines consist mainly of $\mathbf{2} \mathbf{A P Y}^{-\boldsymbol{*}}(99.9 \%)$ and $\mathbf{4 A P Y 2} \mathbf{4}^{-\boldsymbol{*}}(100 \%)$, re-

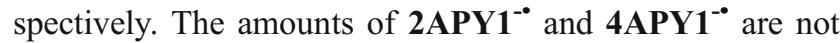
larger than $0.1 \%$. Similarly, the tautomeric mixtures of aniline and 4-aminopyrimidine consist of AN2/4- (100 \%) and $\mathbf{4 A P M} \mathbf{4}^{-\boldsymbol{*}}$ (99.9 \%), respectively. The amounts of $\mathbf{A N 1} \mathbf{1}^{-\bullet}$ and $\mathbf{4 A P M 1 *}{ }^{-}$are not larger than $0.1 \%$.

The importance of the $\mathrm{CH}$ tautomers in the tautomeric mixtures of $\mathbf{A P Y} \mathbf{Y}^{-}$may partially explain the origin of the $\mathrm{CH}$ isomers for the anionic states of nucleobases (cytosine and adenine) $[54,55]$. On the other hand, the change of the compositions of the tautomeric mixtures for neutral and charged forms of aminoazines should also be taken into account for all processes in which the charged radicals can 
be formed, e.g., in electrochemical or photochemical processes and during positive or negative ionization in various types of mass spectrometers when the molecule loses or gains one electron [56-58].

Open Access This article is distributed under the terms of the Creative Commons Attribution License which permits any use, distribution, and reproduction in any medium, provided the original author(s) and the source are credited.

\section{References}

1. Kwiatkowski JS, Person WB (1990) In: Beveridge DL, Lavery R (eds) Theoretical biochemistry and molecular biology. Academic Press, New York

2. Saenger W (1994) Principles of nucleic acid structure. Springer, New York

3. Pozharskii AF, Soldatenkov AT, Katritzky AR (1997) Heterocycles in life and society. Wiley, New York

4. Katritzky AR, Jug K, Oniciu DC (2001) Chem Rev 101:1421-1450

5. Raczyńska ED, Kosińska W, Ośmiałowski B, Gawinecki R (2005) Chem Rev 105:3561-3612, and references therein

6. Raczyńska ED, Stępniewski TM, Kolczyńska K (2011) J Mol Model 17:3229-3239

7. Raczyńska ED, Kolczyńska K, Stępniewski TM (2012) J Mol Model. doi: 10.1007/s00894-012-1358-7)

8. Ladjarafi A, Meghezzi H, Boucekkine A (2004) J Mol Struct (THEOCHEM) 709:129-134

9. Inuzuka K (1996) Nippon Kagaku Kaishi, pp 1007-1008

10. Young MA, DeBoer G, Fujimoto A, Iwasaki N, Traore H, Yourshaw I (1997) Bull Chem Soc Jpn 70:561-569

11. Fujimoto A, Iwasaki N, Hikiba Y, Young MA, Homma K, Inuzuka K (1998) Spectrochim Acta A 54:1779-1792

12. Traore H, Saunders M, Blasiman S (2000) Australian J Chem 53:951-957

13. Inuzuka K, Iwasaki N, Fujimoto A (2001) Nippon Kagaku Kaishi, pp 401-413

14. Alkorta I, Elguero J (2002) J Org Chem 67:1515-1519

15. Inuzuka K (1997) Nippon Kagaku Kaishi, pp 393-399

16. Inuzuka K (1997) Nippon Kagaku Kaishi, pp 100-106

17. Ishikawa H, Fujimoto A (1998) Nippon Kagaku Kaishi, pp 97-98

18. Ishikawa H, Iwata K, Hamaguchi H (2002) J Phys Chem 106:2305-2311

19. Kitamura T, Mochida N, Okita M, Motohashi M, Ishikawa H, Fujimoto A (2007) Spectrochim Acta A 68:979-991

20. Hung FT, Hu WP, Li TH, Cheng CC, Chou PT (2003) J Phys Chem A 107:3244-3253

21. Akai N, Ohno K, Aida M (2005) Chem Phys Lett 413:306-310

22. Akai N, Harada T, Shin-ya K, Ohno K, Aida M (2006) J Phys Chem A 110:6016-6022

23. Akai N, Ohno K, Aida M (2007) J Photochem Photobiol A-Chem 187:113-118

24. Parr RG, Yang W (1989) Density functional theory of atoms and molecular orbital theory. Oxford University Press, New York

25. Becke AD (1993) J Chem Phys 98:5648-5652

26. Lee C, Yang W, Parr RG (1988) Phys Rev B 37:785-789

27. Hehre WJ, Radom L, Schleyer PvR, Pople JA (1986) Ab initio molecular theory. Wiley, New York

28. Frisch MJ, Trucks GW, Schlegel HB, Scuseria GE, Robb MA, Cheeseman JR, Montgomery JA Jr, Vreven T, Kudin KN, Burant
JC, Millam JM, Iyengar SS, Tomasi J, Barone V, Mennucci B, Cossi M, Scalmani G, Rega N, Petersson R, Nakatsuji H, Hada M, Ehara M, Toyota K, Fukuda R, Hasegawa J, Ishida M, Nakajima T, Honda Y, Kitao O, Nakai H, Klene M, Li X, Knox JE, Hratchian HP, Cross JB, Bakken V, Adamo C, Jaramillo R, Gomperts R, Stratmann RE, Yazyev O, Austin AJ, Cammi R, Pomelli C, Ochterski JW, Ayala PY, Morokuma K, Voth GA, Salvador P, Dannenberg JJ, Zakrzewski VG, Dapprich S, Daniels AD, Strain MC, Farkas O, Malick DK, Rabuck AD, Raghavachari K, Foresman JB, Oritz JV, Cui Q, Baboul AG, Clifford S, Cioslowski J, Stefanov BB, Liu G, Liashenko A, Piskorz P, Komaromi I, Martin RL, Fox DJ, Keith T, Al-Laham MA, Peng CY, Nanayakkara A, Challacombe M, Gill PMW, Johnson B, Chen W, Wong MW, Gonzalez C, Pople JA (2004) Gaussian 03, Revision E.01. Gaussian Inc, Wallingford, CT

29. Bertrand W, Bouchoux G (1998) Rapid Commun Mass Spectrom 12:1697-1700

30. Rodríguez-Santiago L, Vendrell O, Tejero I, Sodupe M, Bertran J (2001) Chem Phys Lett 334:112-118

31. Exner O, Bohm S (2006) Collect Czech Chem Commun 71:1239-1255

32. Raczyńska ED, Zientara K, Kolczyńska K, Stępniewski TM (2009) Pol J Chem 83:821-834

33. Raczyńska ED, Kamińska B (2010) J Phys Org Chem 23:823-835

34. Lipping L, Kutt A, Kaupmess K, Koppel I, Burk P, Leito I, Koppel IA (2011) J Phys Chem A 115:10335-10344

35. Raczyńska ED, Hallmann M, Duczmal K (2011) Comput Theor Chem 964:310-317

36. Reynisson J, Steenken S (2002) Phys Chem Chem Phys 4:5353-5358

37. Kumar A, Sevilla MD (2011) J Phys Chem B 115:4990-5000

38. Raczyńska ED, Zientara K, Kolczyńska K, Stępniewski T (2009) J Mol Struct (THEOCHEM) 894:103-111

39. Smith BJ, Radom L (1993) J Am Chem Soc 115:4885-4888

40. Smith BJ, Radom L (1995) J Phys Chem 99:6468-6471

41. Balci K, Akyuz S (2005) J Mol Struct 744-747:909-919

42. Kitamura T, Okita M, Sasaki Y, Ishikawa H, Fujimoto A (2008) Spectrochim Acta A 69:350-360

43. Bludsky O, Sponer J, Leszczynski J, Spirko V, Hobza P (1996) J Chem Phys 105:11042-11050

44. Barfield M, Fagerness P (1997) J Am Chem Soc 119:8699-8711

45. Raczyńska ED, Krygowski TM, Duczmal K, Hallmann M (2006) XVIII International Conference on Physical Organic Chemistry. Warsaw, p. 31 (Book of abstracts)

46. Raczyńska ED, Hallmann M, Kolczyńska K, Stępniewski TM (2010) Symmetry 2:1485-1509

47. Raczyńska ED, Kolczyńska K, Stępniewski TM (2011) Comput Theor Chem 963:176-184

48. Raczyńska ED (2011) Comput Theor Chem 971:38-41

49. Kruszewski J, Krygowski TM (1972) Tetrahedron Lett, pp 3839-3842

50. Krygowski TM, Kruszewski J (1974) Bull Acad Pol Sci. Ser Sci Chim 22:871-876

51. Krygowski TM (1993) J Chem Inf Comput Sci 33:70-78

52. Stefanovic D, Grützmacher HF (1974) Org Mass Spectrom 9:1052-1054

53. Bartmess JE (2011) Negative ion energetic data in NIST Chemistry WebBook., NIST Standard Reference Database Number 69. Linstrom PJ, Mallard WG (eds), National Institute of Standards and Technology, Gaithersburg MD, 20899, htpp://webbook.nist.gov

54. Haranczyk M, Rak J, Gutowski M (2005) J Phys Chem A 109:11495-11503

55. Haranczyk M, Gutowski M, Li X, Bowen KH (2007) Prog Natl Acad Sci USA 104:4804-4807

56. Baek SJ, Choi KW, Choi YS, Kim SK (2002) J Chem Phys 117:2131-2140

57. He YG, Wu CY, Kong W (2004) J Chem Phys 120:7497-7504

58. Mc Laferty FW, Tureček F (1993) Interpretation of Mass Spectra. University Science Books, Mill Valley 